\title{
Efecto del pastoreo sobre el banco de semillas en una estepa de halófitas de la Depresión del Salado
}

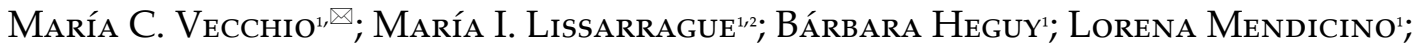 \\ Adriana M. Rodríguez \& Rodolfo A. Golluscio ${ }^{3,4}$ \\ ${ }^{1}$ Universidad Nacional de La Plata. Facultad de Ciencias Agrarias y Forestales. Cátedra de Forrajicultura y Praticultura. La \\ Plata, provincia de Buenos Aires, Argentina. ${ }^{2}$ Universidad Nacional de La Plata. Facultad de Ciencias Agrarias y Forestales. \\ Cátedra de Introducción al Mejoramiento Genético. La Plata, provincia de Buenos Aires, Argentina. ${ }^{3}$ Universidad de Buenos \\ Aires. Facultad de Agronomía. Cátedra de Forrajicultura. Buenos Aires, Argentina. ${ }^{4}$ CONICET. Instituto de Investigaciones \\ Fisiológicas y Ecológicas Vinculadas a la Agricultura (IFEVA). Universidad de Buenos Aires, Facultad de Agronomía. Ciudad \\ Autónoma de Buenos Aires, Argentina.
}

\begin{abstract}
Resumen. El reemplazo del pastoreo continuo por rotativo, o su exclusión, mejoran el suelo y la estructura de la vegetación en la estepa de halófitas de la Depresión del Salado. Sin embargo, se desconoce el efecto del pastoreo sobre el banco de semillas del suelo. El objetivo de este trabajo fue evaluar el efecto de distintos regímenes de pastoreo sobre cuatro atributos del banco de semillas: 1) el tamaño total, 2) su composición en términos de grupos funcionales de plantas (e.g., gramíneas invernales (anuales y perenes), gramíneas estivales (anuales y perenes), monocotiledóneas no gramíneas, leguminosas y dicotiledóneas), 3) la diversidad y 4) la composición florística. El trabajo se realizó en cinco parcelas sometidas a diferentes manejos del pastoreo durante 14 años (dos parcelas bajo pastoreo continuo; dos parcelas bajo pastoreo rotativo y una excluida al pastoreo). El muestreo se efectuó en junio y febrero para estudiar el banco estival e invernal. En las parcelas bajo pastoreo continuo, el tamaño del banco de semillas fue notablemente menor, y del mismo modo ocurrió con la diversidad, la equitatividad y la riqueza florística, especialmente en el banco estival. El pastoreo continuo provocó remplazos de especies muy importantes de los distintos grupos funcionales, particularmente en las gramíneas invernales anuales, en las gramíneas estivales perennes y en las dicotiledóneas, los tres grupos que explican la mayor proporción del banco de semillas. En consecuencia, la composición florística del banco de semillas de las parcelas bajo pastoreo continuo mostró claras diferencias respecto al de las parcelas no pastoreadas o pastoreadas rotativamente. Este trabajo sugiere que el pastoreo continuo constituye un disturbio grave sobre la vegetación de la estepa de halófitas, que reduce de manera severa su potencial de regeneración a partir del banco de semillas respecto a las parcelas sometidas a pastoreo rotativo o no pastoreadas, que resultaron similares entre sí.
\end{abstract}

[Palabras clave: banco de semillas del suelo, manejo del pastoreo, restauración, suelos salino-sódicos]

\begin{abstract}
Aвstract. Grazing effect on the seed bank of a halophytic steppe of the Flooding Pampa, Argentina. Rotational grazing, or even grazing cessation, improves soil and plant community structure on the halophytic steppe of the Flooding Pampa. However, no information exists about the effect of those grazing regimes on the soil seed bank of this fragile plant community. The objective of this work was to evaluate the effect of different grazing regimes on four attributes of the soil seed bank: 1) total size, 2) size and relative contribution of the functional groups of winter grasses (annual and perennial), summer grasses (annual and perennial), non-grass monocotyledonous, legumes and non-legume dicotyledonous, 3) diversity and 4) floristic composition. We studied five plots subjected to different grazing regimes for 14 years (two plots under continuous grazing; two plots under rotating grazing and one excluded from grazing), sampling in June and February to characterize the summer and winter soil seed bank. We found that continuous grazing reduced total seed bank size, and especially that of winter annual grasses and monocotyledonous, and also reduced floristic diversity, richness and evenness, especially in the summer seed bank. In addition, continuous grazing triggered important species replacements within each functional group, especially in the winter annual grasses, summer perennial grasses and dicotyledonous, the three groups explaining most proportion of the soil seed bank. Therefore, plots under continuous grazing were floristically different from those under rotational grazing or ungrazed. This work suggests that continuous grazing is a severe disturbance which can reduce the regeneration potential of the halophytic steppe.
\end{abstract}

[Keywords: grazing management, restoration, saline-sodic soils, soil seedbank] 


\section{INTRODUCCIÓN}

Comprender la dinámica de las comunidades requiere tener en cuenta diferentes aspectos del banco de semillas del suelo, tales como su densidad, composición, persistencia en el suelo y similitud florística con la vegetación establecida (Márquez et al. 2002). Por esa razón, el estudio del banco de semillas constituye un componente esencial de cualquier estrategia de conservación de las especies y de las comunidades vegetales a lo largo del tiempo (Gioria et al. 2014; Tessema et al. 2016). La determinación se puede realizar mediante el banco de semillas germinables del suelo, que es el conjunto de semillas despiertas en condiciones de germinar y representa el potencial regenerativo de la comunidad vegetal (Henderson et al. 1988). El banco de semillas germinables difiere del banco de semillas viables porque en éste pueden quedar semillas durmientes que no son detectadas por este método (Mac Graw and Varek 1989). Por otra parte, la densidad y la composición florística del banco de semillas es el resultado del balance entre el flujo de ingreso de semillas, tanto producidas in situ como arribadas desde otros sitios, y el flujo de salida, integrado, a su vez, por la mortandad (pérdida de viabilidad), la depredación, la germinación, el enterramiento profundo y la migración. En particular, es necesario comprender mejor como los disturbios o los cambios del uso del suelo pueden afectar uno o más de los flujos de entrada o salida y, por lo tanto, el tamaño y la composición del banco de semillas para definir pautas de manejo en la restauración de una comunidad (Chambers and MacMahon 1994).

Tanto la historia de uso del suelo (Thompson 1992) como los disturbios de inundación (Abernethy and Willby 1999), fuego (Laterra et al. 1994) o pastoreo (Roberts 1981; O'Connor 1991; Márquez et al. 2002; Haretche and Rodríguez 2006; Loydi et al. 2012; Loydi 2019), afectan la estructura y el funcionamiento del banco de semillas. Pese a que el pastoreo es el disturbio más distribuido y estudiado en el pastizal natural, la información respecto a sus efectos sobre el banco de semillas es escasa comparada con la existente acerca de sus efectos sobre la vegetación (Haretche and Rodríguez 2006). El pastoreo puede inducir cambios de modo que la composición de los bancos de semillas difiera de la vegetación establecida (Marco et al. 2000; Loydi et al. 2012). En los pastizales se ha observado que, en general, a medida que transcurre el tiempo de ocurrida la perturbación (i.e., el pastoreo), disminuyen las diferencias florísticas entre el banco y la vegetación establecida (Hopfensperger 2007). El pastoreo continuo intenso es una de las fuerzas disruptivas que reducen el número y la proporción de especies palatables en el banco de semillas (Marone et al. 2021). A medida que aumenta la intensidad del pastoreo, suele disminuir la abundancia de las gramíneas perennes dominantes en la vegetación $\mathrm{y}$, en consecuencia, se reduce su abundancia en el banco de semillas. En cambio, en el banco suele haber una densidad elevada de semillas de especies anuales y de dicotiledóneas (O'Connor and Pickett 1992; Haretche and Rodríguez 2006), e incluso de monocotiledóneas no gramíneas (Roberts 1981). Las especies anuales y dicotiledóneas se tornan dominantes en la vegetación de las áreas sometidas a disturbios intensos; éstas presentan mayor similitud entre la composición florística del banco de semillas del suelo y de la vegetación establecidas que en áreas menos disturbadas.

La Pampa Deprimida, que incluye la Depresión del Salado y la Depresión de Laprida, cubre $\sim 9$ millones de hectáreas en la provincia de Buenos Aires, Argentina. Es una de las regiones de pastizales más extensas del país (Oyarzabal et al. 2018). La heterogeneidad de su vegetación está asociada a las variaciones topográficas y de hidromorfismo, de salinidad o de sodicidad de los suelos (Perelman et al. 2001). En la región se identificaron cuatro grandes unidades de vegetación: praderas de mesófitas, praderas húmedas de mesófitas, praderas de hidrófitas y estepas de halófitas (Perelman et al. 2001; Burkart et al. 2005). La estepa de halófitas ocupa 1.6 millones de hectáreas. Presenta una distribución espacial intrincada asociada a su microtopografía compleja, que determina que sus comunidades suelan disponerse en mosaicos donde alternan la pradera húmeda de mesófitas y la pradera de hidrófitas (León et al. 1979). La estepa de halófitas se desarrolla sobre todo en niveles topográficos bajos con altos niveles de sodicidad o de salinidad en casi todo su perfil (Lavado and Taboada 1988). Tal ambiente es uno de los que presenta mayores restricciones para el establecimiento de especies propias de ambientes más fértiles, ya sean exóticas o nativas (Chaneton et al. 2002; Puhl et al. 2014; Vecchio et al. 2019). Las principales especies presentes en esta comunidad son Distichlis spicata, D. scoparia, Sporobolus pyramidatus, Hordeum stenostachys, Puccinelia glaucescens, Pappophorum mucronulatum, todas gramíneas 
nativas y la mayoría (excepto Hordeum spp.) con síndrome fotosintético $\mathrm{C}_{4} \mathrm{y}$ crecimiento primavero-estivo-otoñal, y dicotiledóneas herbáceas como Spergula sp., Lepidium sp. y Acicarpha procumbens. Se destaca además la presencia del alga cianofícea Nostoc commune (Vecchio et al. 2019).

En otras comunidades de la Pampa Deprimida (e.g., la pradera húmeda de mesófitas), el pastoreo continuo promueve el reemplazo de especies nativas o naturalizadas por exóticas, lo que se refleja en un cambio en la proporción de los grupos funcionales (Chaneton et al. 2002). Al comparar el efecto del pastoreo rotativo respecto del continuo sobre la vegetación, en las praderas húmedas de mesófitas el pastoreo rotativo incrementó la cobertura de grupos funcionales de alto valor forrajero (gramíneas invernales anuales y leguminosas) y en las praderas de hidrófitas aumentó la cobertura de gramíneas palustres y disminuyó la de dicotiledóneas (Jacobo et al. 2006). En las estepas de halófitas bajo pastoreo continuo, a medida que aumenta la presión de pastoreo disminuye la cobertura vegetal y la de broza, y aumenta la proporción de suelo desnudo. Sin embargo, debido a las restricciones ambientales mencionadas, no se registran grandes cambios en la proporción de los grupos funcionales (Vecchio et al. 2019). En cambio, la exclusión del pastoreo y el pastoreo planificado promovieron reemplazos sutiles entre especies nativas o naturalizadas dentro de los principales grupos funcionales, como las gramíneas invernales anuales y perennes o las gramíneas estivales perennes, así como aumentos en la cobertura total de las gramíneas invernales y estivales, tanto anuales como perennes, todos los cuales condujeron a aumentos del valor zootécnico de la comunidad (Vecchio et al. 2019). Es probable que estos cambios florísticos en la comunidad tengan su correlato en la composición del banco de semillas.

Uno de los factores que desalienta el estudio de la dinámica de las comunidades naturales, y en particular la de sus bancos de semillas, es su heterogeneidad florística elevada. En general, se asume que una forma de simplificar estos estudios es agrupando a las especies en grupos funcionales, es decir conjuntos de especies que juegan un rol ecológico similar en un ecosistema sobre la base de determinados atributos biológicos comunes (Noble and Gitay 1996; Jacobo et al. 2006). Así, en distintas comunidades de la Depresión del Salado se han definido grupos funcionales como gramíneas anuales y perennes, invernales y estivales, monocotiledóneas no gramíneas, leguminosas y otras dicotiledóneas (Jacobo et al. 2006). Usar grupos funcionales facilitaría el estudio de la vegetación y del banco de semillas del suelo. La disponibilidad de semillas en el suelo de cada uno de estos grupos puede dar indicios acerca de la capacidad de recuperación de la comunidad después de un disturbio.

El objetivo general de este trabajo fue estudiar el efecto de diferentes manejos del pastoreo sobre el banco de semillas de una estepa de halófitas de la Pampa Deprimida y su variación estacional. Los objetivos específicos fueron evaluar el efecto de distintos regímenes de pastoreo y la estación del año sobre cuatro atributos del banco de semillas: 1) el tamaño total, 2) el tamaño y la importancia relativa de los grupos funcionales mencionados arriba, 3) la diversidad y 4) la composición florística.

\section{Materiales y Métodos}

\section{Sitio de estudio}

El estudio se llevó a cabo en el noreste de la Pampa Deprimida, en la localidad de Vieytes, partido de Magdalena (35ำ13⒌372 S - 57³7'5.152 O), provincia de Buenos Aires. El clima de la zona es templado húmedo sin estación seca (952 mm de precipitación media anual y $15.2{ }^{\circ} \mathrm{C}$ de temperatura media anual; serie de 30 años) con lluvias distribuidas a lo largo de todo el año; se caracteriza por el déficit de lluvias en verano y el exceso en invierno. Típicamente, los suelos tienen un horizonte arcilloso de baja permeabilidad y alto contenido de sales sódicas, al menos subsuperficialmente, que desencadenan la frecuente alternancia de sequías y anegamientos. La determinación del banco de semillas se realizó en estepas de halófitas que ocupan los suelos con altos niveles de salinidad y sodicidad desde la superficie o muy cerca de la superficie, alfisoles (natracualfes), ubicadas en el paisaje en áreas planas, tendidas y deprimidas con pendientes menores a $0.1 \%$.

La comunidad vegetal del sitio de estudio es bastante homogénea desde el punto de vista estructural. Está integrada por especies de ciclo otoño-inverno-primaveral y primaveroestivo-otoñal en proporciones similares. Su característica más sobresaliente es la escasa cobertura $(\sim 40 \%)$. La fisonomía de esta comunidad presenta dos estratos continuos: 
uno bajo, compuesto por hierbas como Acicarpha procumbens y Petunia parviflora junto a gramíneas muy preferidas por el ganado como Paspalum vaginatum, Jarava plumosa (ex Stipa papposa), Sporobolus pyramidatus, Sporobolus indicus, Stapfochloa berroi, Polypogon elongatus (ex Chaetotropis elongata) y Hordeum stenostachys, entre otras especies, y otro estrato con más de $15 \mathrm{~cm}$ de altura, compuesto por gramíneas estivales perennes, principalmente Distichlis spp. y dicotiledóneas como Grindelia discoidea o Pterocaulum subvirgatum. A estas especies se suman gramíneas anuales como Gaudinia fragilis, Leptochloa fusca (ex Diplachne uninervia), Lolium multiflorum, Haynardia cylindrica (ex Monerma) y leguminosas como Melilotus indicus y Lotus tenuis. La abundancia elevada de Distichlis spp. o de especies rastreras como Sporobolus pyramidatus podría ser consecuencia del manejo continuo e intenso del pastoreo. La vegetación actual no ha sido afectada por la agricultura, pero sí por el pastoreo y la inundación. Como la agriculturización en la región ha desplazado la ganadería hacia pastizales nativos relictuales con limitaciones severas para la agricultura, como la estepa de halófitas, estos pastizales sufrieron un importante aumento en la presión del pastoreo, intenso y continuo, que modificó la estructura de la vegetación.

\section{Arreglo espacial del ensayo}

El estudio del banco de semillas se realizó en tres establecimientos dedicados a la cría de ganado vacuno, ubicados en los alrededores de la localidad de Vieytes, partido de Magdalena. En cada establecimiento se seleccionaron parcelas con predominio de estepa de halófitas en las que el suelo se identificó como Natracualf típico. En uno de los establecimientos, 'El Amanecer', que pertenece a la Universidad Nacional de la Plata, se seleccionaron tres parcelas, sujetas desde hace 14 años a pastoreo rotativo (dos parcelas) o exclusión del pastoreo (una parcela). En cada uno de los otros dos establecimientos se seleccionó una parcela sujeta a pastoreo continuo desde hace varias décadas. Las cuatro parcelas pastoreadas recibieron similar categoría de animales (vacas adultas Aberdeen Angus) y una carga media anual de $0.8 /$ ha. Los potreros tienen $\sim 10$ ha, excepto la parcela excluida, que tiene 1 ha. De este modo, las parcelas a comparar fueron: clausurado al pastoreo por 14 años (CL), pastoreo rotativo por 14 años (R1 y R2) y pastoreo continuo (C1 y C2) (Figura 1).

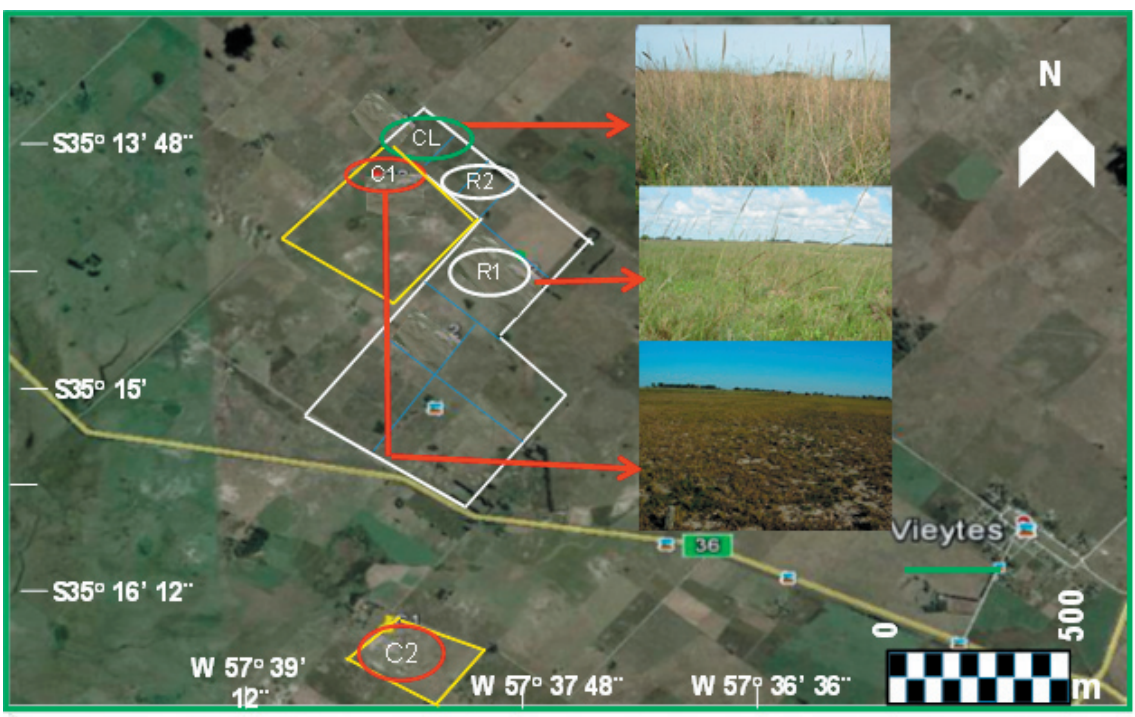

Figura 1. Ubicación del sitio de estudio en la localidad de Vieytes (partido de Magdalena, provincia de Buenos Aires), perteneciente a la unidad de vegetación Pampa Deprimida ( $n^{\circ} 33$ en el mapa de vegetación de la Argentina (Oyarzabal et al. 2018); ver mapa a la izquierda). Sobre la imagen de Google Earth@ de la derecha se muestran las parcelas bajo pastoreo continuo (C1 y C2), bajo pastoreo rotativo (R1 y R2) y excluida al pastoreo vacuno (CL). Las fotografías muestran la estructura de la vegetación del sitio excluido al pastoreo (arriba), bajo pastoreo rotativo (centro) y bajo pastoreo continuo (abajo).

Figure 1. Location of the study site in Vieytes (Magdalena county, province of Buenos Aires) belonging to the vegetation unit Pampa Deprimida ( $\mathrm{n}^{\circ} 33$ in the map of vegetation from Oyarzabal et al. (2018); see map at left). Over the Google Earth@ image at right, we show the plots under continuous grazing $(\mathrm{C} 1$ and $\mathrm{C} 2)$ under rotational grazing (R1 and $\mathrm{R} 2)$ and excluded to cattle grazing (CL). The photographs show the structure of the vegetation of the site excluded from grazing (above), under rotating grazing (center) and under continuous grazing (below). 
En las parcelas bajo pastoreo rotativo se realizan pastoreos planificados con períodos de descanso de entre 60 días (primavera) y 150 días (invierno), con una permanencia de los animales bajo pastoreo de entre 3 y 5 días y una carga animal instantánea de entre 30 a $50 \mathrm{EV} /$ ha, que asegura una intensidad de pastoreo moderada sobre las especies preferidas (remanente $\geq 10 \mathrm{~cm}$ ). En las parcelas bajo pastoreo continuo, los animales permanecen en el mismo potrero durante todo el año, lo cual da lugar a una intensidad de pastoreo elevada sobre las especies preferidas, ya que permite la selección y el sobrepastoreo de las mismas. En consecuencia, se asume que la secuencia clausura-pastoreo rotativopastoreo continuo representa un gradiente de intensidad de pastoreo creciente.

El ensayo no satisface completamente los principios de diseño experimental al carecer de repeticiones verdaderas para los tres manejos comparados (pastoreo continuo, rotativo y clausura). Estas limitaciones, relativamente frecuentes en estudios mensurativos como el presente (Hurlbert 1984; Chaneton et al. 1988), obedecen a la dificultad de hallar, en establecimientos independientes, potreros con stands de estepas de halófitas sujetos a alguna de las tres condiciones de pastoreo durante varios años. Sin embargo, consideramos que este trabajo aportará una descripción inédita sobre la composición del banco de semillas de este tipo de comunidades bajo distintos manejos del pastoreo, que podrá servir de base para otros estudios más rigurosos, incluso manipulativos (Hurlbert 1984).

Los censos de vegetación (Braun Blanquet 1979) realizados en las 5 parcelas durante la primavera (noviembre de 2011) y principios de otoño (marzo de 2012) (datos incluidos en Vecchio et al. 2019) no mostraron diferencias en la composición de grupos funcionales, pero sí cambios florísticos dentro de los grupos más conspicuos, particularmente cambios en sus especies dominantes (arbitrariamente, aquéllas con cobertura $>10 \%$ ). En efecto, en las gramíneas invernales anuales, Hordeum pusillum fue dominante bajo pastoreo continuo, mientras que Gaudinia fragilis lo fue bajo pastoreo rotativo o clausura. En las gramíneas perennes invernales, Hordeum stenostachys fue dominante en las parcelas bajo pastoreo rotativo, pero estuvo ausente en las parcelas clausuradas y en las pastoreadas en forma continua. En las gramíneas estivales perennes, Distichlis spp. fue dominante bajo pastoreo continuo, mientras que Stapfochloa (ex Chloris) berroi fue dominante bajo pastoreo rotativo o clausura y Sporobolus pyramidatus fue dominante en las parcelas pastoreadas, aunque estuvo ausente en las clausuradas (Anexo I).

\section{Estudio del banco de semillas}

El muestreo se realizó en junio de 2012, cuando las semillas de las especies $C_{4}$ presentes en el suelo aún no habían germinado (banco de semillas estival, BSE) y en febrero de 2013, cuando todavía no habían germinado las semillas de las especies $\mathrm{C}_{3}$ (banco de semillas invernal, BSI). En cada parcela se tomaron cuatro muestras compuestas, cada una integrada por 10 submuestras distribuidas al azar. Cada submuestra se extrajo con un barreno de $2.5 \mathrm{~cm}$ de diámetro y $5 \mathrm{~cm}$ de profundidad. Así se totalizó un volumen de $245.3 \mathrm{~cm}^{3}$ para cada muestra compuesta, valor que se encuentra dentro de lo recomendado para registrar la mayoría de las especies presentes en el suelo (Roberts 1981).

Para evaluar el banco de semillas germinables se utilizó el método de emergencia de plántulas descrito por Roberts (1981). Las muestras se dejaron secar a temperatura ambiente hasta que se las pudo disgregar para eliminar fragmentos de plantas y piedras. El material resultante de cada una de las cuatro muestras de cada parcela se colocó en dos bandejas plásticas de $25 \mathrm{~cm}$ de largo por $18 \mathrm{~cm}$ de ancho sobre una capa de $1 \mathrm{~cm}$ de sustrato inerte. Estas bandejas se llevaron a una cámara con un régimen diario de alternancia de 12 horas de luz y 12 horas de oscuridad y 22 a 25 ${ }^{\circ} \mathrm{C}$ de temperatura, y se las regó cada 2 días. Las muestras extraídas en ambos muestreos se mantuvieron durante un mes a $5{ }^{\circ} \mathrm{C}$ antes de colocarlas en las bandejas a fin de romper la latencia de las semillas que requerían ese estímulo (Roberts 1981; Bolaños et al. 2019).

Seregistraronlas plántulasemergidasdurante cinco meses; se identificó su género y especie, y se las clasificó en los siete grupos funcionales definidos para la vegetación establecida: gramíneas invernales anuales (GIA) y perennes (GIP), gramíneas estivales anuales (GEA) y perennes (GEP), monocotiledóneas no gramíneas (M), leguminosas (L) y otras dicotiledóneas (D) (Jacobo et al. 2006).

\section{Análisis de datos}

Para evaluar las diferencias asociadas a los distintos regímenes de pastoreo se 
consideraron como tratamientos las cinco parcelas. Tal decisión obedeció a que sólo se contaba con una clausura y que las dos repeticiones verdaderas de cada sistema de pastoreo no eran estrictamente comparables porque las dos parcelas bajo pastoreo rotativo (R1 y R2) estaban en el mismo establecimiento que la clausura, pero las dos parcelas bajo pastoreo continuo (C1 y C2) estaban en otros dos establecimientos. Asimismo, se consideró a los cuatro sitios dentro de cada parcela como repeticiones, aunque estrictamente eran pseudorepeticiones (Hurlbert 1984). Al no contar con repeticiones verdaderas de los tres regímenes de pastoreo comparados, los datos utilizados para el análisis constituyen los 5 'tratamientos' (=parcelas). Esas debilidades, sumadas a las ya mencionadas acerca del arreglo espacial de las parcelas, impiden asignar significancias estadísticas a las diferencias halladas entre tipos de pastoreo e incluso extraer conclusiones extrapolables a otras situaciones similares de la misma región.

Con esas restricciones, los datos de densidad de semillas y diversidad florística fueron analizados mediante ANVA, utilizando un arreglo factorial de 5 parcelas $\times 2$ estaciones del año. La proporción de los distintos grupos funcionales en cada muestra ( $p$ ) fue calculada como el cociente entre la densidad de plántulas de cada grupo funcional y la densidad total de plántulas de cada muestra y fue sometida a la transformación angular (arcoseno $\sqrt{ } \mathrm{p}$ ) antes de realizar el ANVA. Las medias se compararon con la prueba de Tukey, utilizando - al igual que en los ANVA - el paquete Infostat (Di Rienzo et al. 2018). Para cada parcela y para las dos estaciones del año estudiadas se calculó la densidad de semillas total y para cada grupo funcional (número total de plántulas $/ \mathrm{m}^{2}$ ) y la densidad relativa de cada grupo funcional en cada parcela (número de plántulas $/ \mathrm{m}^{2}$ de un grupo funcional/número total de plántulas en esa parcela). También se calculó la diversidad florística y sus dos componentes, la riqueza y la equitatividad. La diversidad se estimó mediante el índice de Shannon y Weaver (1963)

$$
\mathrm{H}^{\prime}=-\sum \mathrm{p}_{\mathrm{i}}^{*} \ln \mathrm{p}_{\mathrm{i}}
$$

donde $\mathrm{H}^{\prime}$ es la diversidad y $\mathrm{p}_{\mathrm{i}}$ es la densidad relativa de cada una de las i especies presentes en cada parcela $\left(\mathrm{p}_{\mathrm{i}}=\right.$ densidad $_{\mathrm{i}} / \sum$ densidad $\left._{\mathrm{i}}\right)$. La riqueza florística $(S)$ se calculó como el número de especies registradas en cada parcela y la equitatividad como el cociente entre el índice de Shannon y Weaver $\left(\mathrm{H}^{\prime}\right)$ y la máxima diversidad (H'max), expresada como ln S (Magurran 2004).

La composición florística delbanco desemillas se comparó con la de la vegetación establecida en los mismos potreros (Vecchio et al. 2019; ver Anexo). Dicho relevamiento de vegetación fue realizado el año anterior al muestreo de banco de semillas y, por otra parte, dada la intrincada matriz topográfica del paisaje, el banco de semillas de un micrositio dado muy probablemente reciba semillas provenientes de stands vecinos de la misma e, incluso, de otras comunidades. Por esas razones sólo se realizó una comparación muy general entre la vegetación establecida y el banco de semillas. La misma consistió en calcular el índice de similitud de Jaccard (Real and Vargas 1996) entre las especies de cada grupo funcional encontradas en el relevamiento florístico y en el banco de semillas, sin intentar evaluar cómo variaba dicho índice entre fechas de muestreo ni entre parcelas. El índice de Jaccard calcula la similitud entre dos conjuntos de especies cualquiera como el cociente entre las especies comunes a ambos conjuntos y el total de especies diferentes que aparecieron en ambos.

Para describir la variación en la composición florística del banco de semillas entre las 5 parcelas y las dos estaciones se realizó, en primer término, un ordenamiento de los datos mediante un análisis de componentes principales (ACP). A tal efecto se utilizó la densidad relativa de semillas de cada especie en cada relevamiento del banco. Este procedimiento dio como resultado una matriz de 40 muestras (5 parcelas $\times 4$ sitios/parcela $\times 2$ estaciones) $\times 43$ especies presentes en al menos $10 \%$ de los censos realizados en alguno de los dos muestreos. Otras once especies fueron excluidas de los análisis multivariados por haber estado presentes en menos del 10\% de ambosmuestreos. Lasmismas correspondieron a 5 de los 7 grupos funcionales (la excepción fueron las gramíneas invernales anuales y las leguminosas): Polypogon elongatus (ex Chaetotropis elongata) y Hordeum stenostachys (GIP), Digitaria ciliaris (GEA), Aristida murina, Panicum bergii y Sporobolus platensis (GEP), Oxalis spp. y Soliva macrocephala (D) y Carex spp., Cyperus entrerrianus y Zephyranthes minima (M). Se utilizó la matriz de varianzascovarianzas para evaluar la similitud entre especies (Legendre and Legendre 1998). 
Para probar las diferencias multivariadas en la composición de especies entre las 40 muestras relevadas y detectar grupos de muestras internamente homogéneos y estadísticamente diferentes entre sí se aplicó el procedimiento de permutación de respuesta múltiple (MRPP, en inglés) (Biondini et al. 1998) sobre la misma matriz de 40 muestras $x 43$ especies. Finalmente, para identificar las especies responsables de estas diferencias, sobre la matriz original de 40 muestras x 54 especies (eliminando la restricción de cobertura $>10 \%$ ) se realizó un análisis de especies indicadoras y una prueba de Monte Carlo que incluyó como variables de agrupación las dos estaciones del año y los tres manejos del pastoreo. Se pasó de 5 parcelas a 3 manejos del pastoreo para simplificar el análisis, teniendo en cuenta la similitud hallada en la prueba MRPP entre las dos parcelas bajo pastoreo continuo y entre las dos parcelas bajo pastoreo rotativo. Todos los análisis multivariados se hicieron con el paquete PC-ORD TM versión 4 (McCune and Mefford 1999).

\section{Resultados}

\section{Tamaño del banco de semillas}

Las muestras de banco invernal tuvieron mayor densidad total de plántulas emergidas que las de banco estival (6616 vs. 5003 plántulas/ $\mathrm{m}^{2}$ ), mientras que las parcelas excluidas al pastoreo y bajo pastoreo rotativo registraron un tamaño mayor (4554 a 10625 plántulas/m²) que las parcelas bajo pastoreo continuo, que nunca superaron las 4000 plántulas $/ \mathrm{m}^{2}$ (1205 a 3929 plántulas $/ \mathrm{m}^{2}$ ) (Tabla 1, medias y desvíos estándar en la leyenda de la Figura 2).

\section{Grupos funcionales}

La densidad de semillas de los distintos grupos funcionales mostró diferencias más entre estaciones que entre parcelas (Tabla 1). El aumento de la densidad de semillas de las GIA entre verano e invierno (de 929 a 3670 plántulas $/ \mathrm{m}^{2}$, respectivamente) fue muy importante, pero inferior en porcentaje de cambio a las reducciones registradas entre

Tabla 1. Resultados de los análisis de varianza aplicados sobre la densidad total de plántulas emergidas (plántulas $/ \mathrm{m}^{2}$ ), la proporción de la misma (densidad de plántulas de cada grupo/densidad de plántulas total; datos sometidos a la transformación angular previo al análisis de varianza) correspondiente a los siete grupos funcionales analizados y la densidad de plántulas emergidas de cada grupo (plántulas $/ \mathrm{m}^{2}$ ). Los grupos funcionales analizados fueron gramíneas invernales anuales (GIA) y perennes (GIP), gramíneas estivales anuales (GEA) y perennes (GEP), monocotiledóneas no gramíneas (M), leguminosas (L) y otras dicotiledóneas (D). Se consignan los valores de F de Snedecor y P para los dos factores incluidos en el ANVA (estación E y parcela P) y para la interacción entre ellos. Cuando la interacción E x P no fue significativa, se consignan los resultados de la prueba de Tukey comparando las medias del factor o factores que mostraron diferencias significativas; letras distintas (ordenadas en forma creciente desde la media más baja hacia la más alta: A-B-C) indican diferencias significativas al $5 \%$.

Table 1. ANOVA results for total seed bank (emerged seedlings $\left./ \mathrm{m}^{2}\right)$, proportion of total density corresponding to the seven functional groups (\%; angular transformed data) and seed bank density of each group (emerged seedlings $/ \mathrm{m}^{2}$ ). The functional groups were winter grasses (annual and perennial), summer grasses (annual and perennial), no grass monocotyledoneous, legumes and no legume dicotyledonous. We report the Snedecor's F and P for the factors season, plot and the interaction season $x$ plot. When interaction was not significant, different letters indicate the differences between levels of each significant factor (Tukey test, $\mathrm{P}<0.05$; letters ordered from the lowest to the highest mean: $\mathrm{A}<$ $\mathrm{B}<\mathrm{C})$.

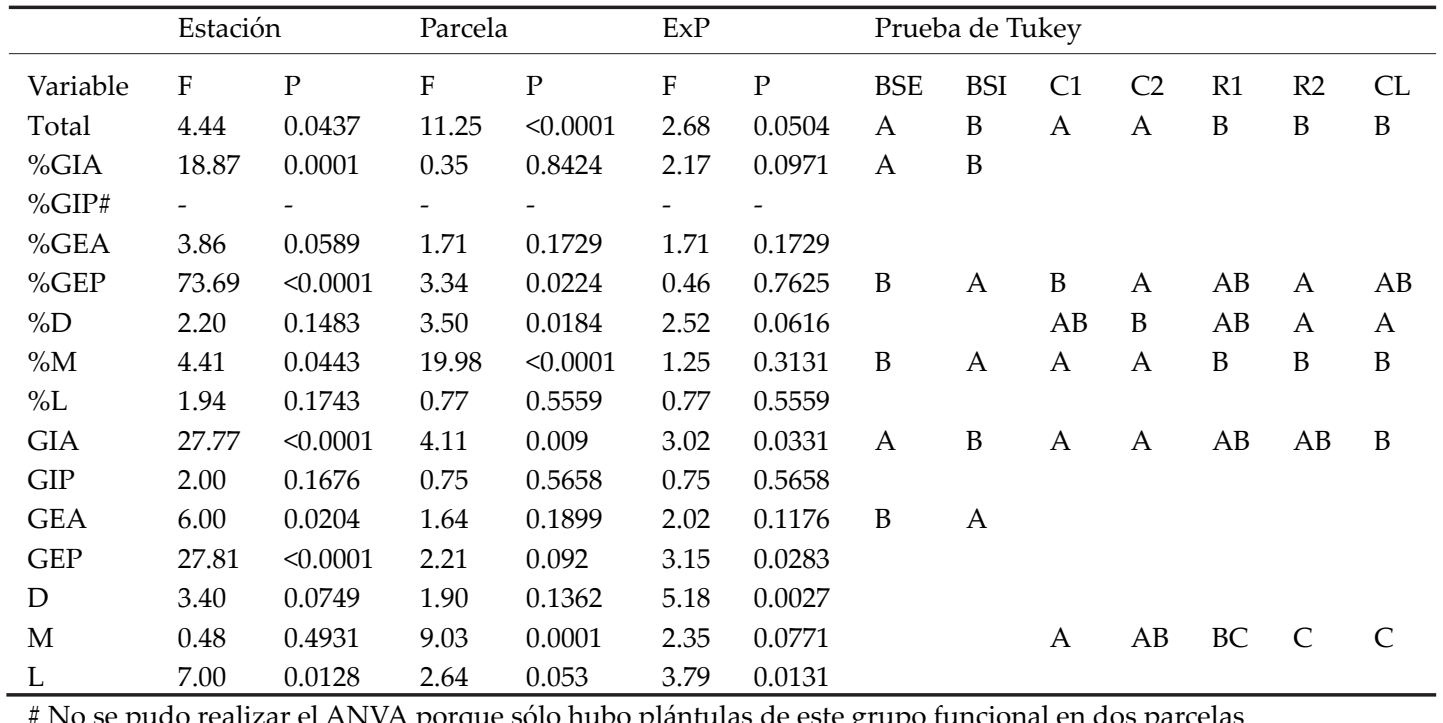

\# No se pudo realizar el ANVA porque sólo hubo plántulas de este grupo funcional en dos parcelas 


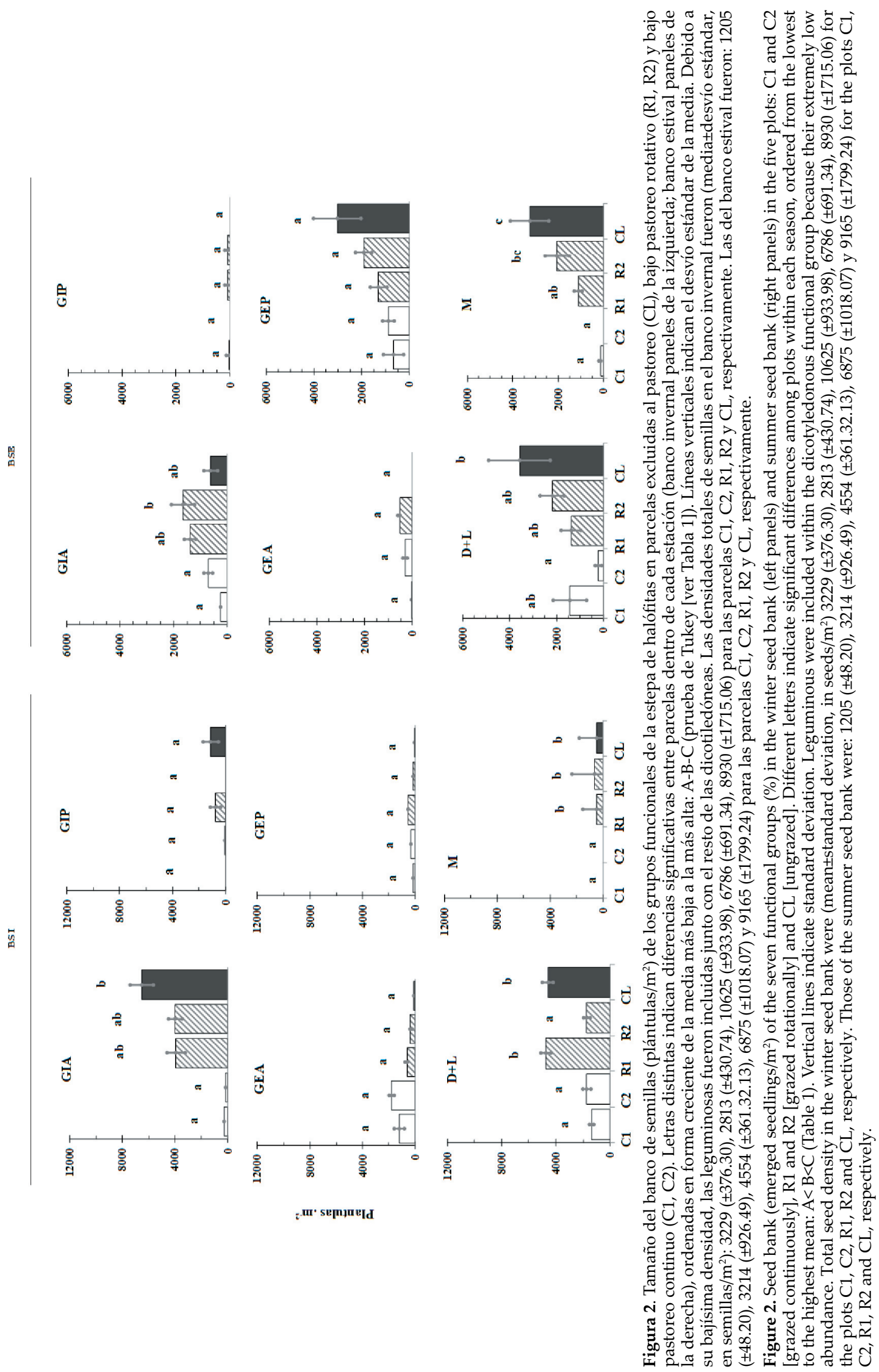


verano e invierno por los otros dos grupos que mostraron diferencias estacionales: de 80 a 9 plántulas $/ \mathrm{m}^{2}$ en las GEA y de 1563 a 161 plántulas $/ \mathrm{m}^{2}$ en las GEP. Por su parte, las monocotiledóneas no gramíneas y las GIA fueron las únicas que mostraron un patrón claro de variación asociado al sistema de pastoreo: sus densidades mínimas ocurrieron bajo pastoreo continuo, y las máximas, en ausencia de pastoreo (Tabla 1 y Figura 2).

Como consecuencia de los patrones descriptos para la densidad de semillas en el banco total y las de cada grupo funcional, la importancia relativa de los 7 grupos funcionales varió marcadamente entre las dos estaciones de muestreo (Tabla 1). El banco invernal mostró mayor proporción de GIA que el banco estival (54 vs. $23 \%$, respectivamente), pero menor de GEP y M (3 vs. 35\% y 11 vs. $17 \%$, respectivamente). Por su parte, las diferencias entre parcelas se registraron en las monocotiledóneas no gramíneas (virtualmente ausentes en las parcelas bajo pastoreo continuo y con porcentajes de $\sim 20 \%$ en las parcelas bajo pastoreo rotativo o sin pastoreo [18-25\%]), y las dicotiledóneas (que no difirieron entre las dos estaciones de muestreo y alcanzaron su menor importancia en la clausura [16\%] y su mayor importancia en las parcelas bajo pastoreo continuo [28 y $48 \%$ en C1 y C2, respectivamente]).

\section{Diversidad florística}

Se identificaron 54 especies en el banco de semillas germinable: 6 gramíneas invernales (4 anuales y 2 perennes), 17 gramíneas estivales (3 anuales y 14 perennes), 22 dicotiledóneas no leguminosas, 7 monocotiledóneas no gramíneas y 2 leguminosas. El BSE tuvo más especies que el BSI (45 vs. 28 especies, respectivamente) y ambos estuvieron representados por especies pertenecientes a todos los grupos funcionales definidos (Tabla 2; primeras 13 columnas).

Las especies más abundantes en el banco de semillas coincidieron parcialmente con las dominantes en la vegetación (Tabla 2 vs. Anexo). Entre las gramíneas invernales anuales (GIA), en las parcelas bajo pastoreo continuo a la antes mencionada Hordeum pusillum se sumó Haynardia cylindrica, mientras que las parcelas bajo pastoreo rotativo o clausura se caracterizaron por la dominancia de Gaudinia fragilis, como se registra en los censos de vegetación. Sin embargo, en el banco de semillas de la clausura cobró gran importancia Lolium multiflorum. Por su parte, las gramíneas invernales perennes (GIP) estuvieron prácticamente ausentes del banco de semillas (no así de la vegetación) y las gramíneas estivales anuales (GEA) fueron muy escasas tanto en la vegetación como en el banco de semillas. Llamativamente, en el grupo de las gramíneas estivales perennes, las especies dominantes en la comunidad (Distichlis spp. en las parcelas bajo pastoreo continuo y Stapfochloa berroi en las parcelas bajo pastoreo rotativo o clausura) fueron muy poco abundantes en el banco de semillas, y Sporobolus pyramidatus (dominante en las parcelas bajo pastoreo, ya sea continuo o rotativo), sólo mostró abundante densidad en el banco de semillas de las parcelas bajo pastoreo continuo. En el caso de las dicotiledóneas(D), se destacaron Spergula laevis (muy abundante en el banco de semillas de las parcelas bajo pastoreo continuo y en los censos de vegetación realizados en una de ellas) y Plantago myosurus (abundante en el banco estival de una de ellas, pero muy escasa en la vegetación establecida). Entre las leguminosas (L), Melilotus indicus y Lotus tenuis aparecieron tanto en la vegetación como en el banco de semillas, pero en ambos casos fueron muy escasas. Finalmente, entre las monocotiledóneas no gramíneas $(\mathrm{M})$ no hubo ninguna especie dominante en los censos de vegetación, pero, en cambio, Cyperus reflexus fue muy abundante en el banco de semillas de las parcelas bajo pastoreo rotativo y clausura. Estas similitudes y diferencias entre la composición florística de la vegetación establecida y la del banco de semillas tiene su correlato en el índice de similitud entre ambos, máximo en las gramíneas invernales anuales y las leguminosas, intermedio en las dicotiledóneas no leguminosas y en las monocotiledóneas no gramíneas, algo menor en las gramíneas estivales perennes y mínimo en las gramíneas invernales perennes y las gramíneas estivales anuales (Tabla 2).

En ambas estaciones, la riqueza de cada parcela tendió a ser mayor en el BSE que en el BSI (9.85 vs. 6.95), excepto en una de las parcelas bajo pastoreo continuo (C1) y otra bajo pastoreo rotativo (R1, aunque en este caso, los valores de ambas estaciones fueron muy similares). La diversidad mostró esencialmente el mismo patrón. En el relevamiento estival, tanto la riqueza como la diversidad fueron máximas en las parcelas R1, R2 y en la clausura, y mínimas en las parcelas bajo pastoreo continuo. En cambio, en el relevamiento invernal las diferencias entre 
Tabla 2. Densidad relativa de las especies encontradas en estepas de halófitas (en \% de la densidad total) para cada grupo funcional en los sitios clausurados al pastoreo (CL), bajo pastoreo rotativo (R1 y R2) y pastoreo continuo (C1 y C2), tanto para el banco de semillas estival (BSE) como para el banco de semillas invernal (BSI). Para cada grupo funcional se consigna entre paréntesis el índice de similitud de Jaccard (Real and Vargas 1996) con respecto a las especies halladas en el relevamiento de vegetación (Vecchio et al. 2019) (ver Anexo). Los asteriscos identifican a las 11 especies incluidas en este análisis que habían sido excluidas del ACP. Se consignan los resultados de la prueba de Monte Carlo comparando los sitios de los tres sistemas de pastoreo (se promediaron R1 y R2 y C1 y C2) en las dos estaciones, indicando el valor indicador $(\mathrm{P}<0.01)$ de cada especie en cada una de las comparaciones de interés (análisis de especies indicadoras y prueba de Monte Carlo): entre estaciones ('Estac.') y entre los 3 sistemas de pastoreo tomados de a pares.

Table 2. Relative density (percent of total density) of the 54 species of seven functional groups found in the soil seed bank of the halophytic steppe in plots ungrazed (CL), under rotational grazing (R1 and R2) or under continuous grazing (C1 and C2), for both summer (BSE) and winter soil seed bank (BSI). For each functional group we show between brackets the Jaccard's similarity index (Real and Vargas 1996) respect to the species found in the plant community (Vecchio et al. 2019) (see Appendix). Asterisks identify the 11 species excluded from the principal component analysis. We report the results of Indicator species analysis of Montecarlo test: indicator value $(\mathrm{P}<0.01)$ of each species for each comparison (between seasons or between pairs of grazing regimes (both $\mathrm{C} 1$ and $\mathrm{C} 2$, and R1 and R2 were averaged). We only show the significant $(\mathrm{P}<0.05)$ indicator values, highlighting in bold those significant at $0.05<\mathrm{P}<0.01$

\begin{tabular}{|c|c|c|c|c|c|c|c|c|c|c|c|c|c|c|c|c|}
\hline \multirow[b]{2}{*}{ GF } & \multirow[b]{2}{*}{ Especie } & \multicolumn{2}{|c|}{ Acrónimo } & \multicolumn{4}{|c|}{ Banco de semillas estival } & \multicolumn{5}{|c|}{ Banco de semillas invernal } & \multicolumn{4}{|c|}{$\begin{array}{c}\text { Análisis de especies } \\
\text { indicadoras }\end{array}$} \\
\hline & & & $\mathrm{C} 1$ & $\mathrm{C} 2$ & R1 & R2 & CL & $\mathrm{C} 1$ & $\mathrm{C} 2$ & R1 & R2 & CL & Estac. & $\mathrm{R} / \mathrm{C}$ & $\mathrm{CL} / \mathrm{C}$ & $\mathrm{R} / \mathrm{CL}$ \\
\hline \multirow[t]{4}{*}{ GIA } & Gaudinia fragilis & G.fra & & & 23.1 & 22.0 & 2.8 & & 3.1 & 29.2 & 53.8 & 35.7 & & 35.0 & 22.3 & 51.5 \\
\hline & $\begin{array}{l}\text { Haynardia (ex } \\
\text { Monerma) cylindrica }\end{array}$ & H.cyl & 3.6 & 14.6 & 8.1 & 2.5 & & 46.5 & 30.0 & 6.0 & 2.6 & $0.9^{*}$ & 39.9 & 46.7 & 40.4 & 36.9 \\
\hline & Hordeum pusillum & H.pus & 20.2 & 9.9 & & & & 4.3 & 10.2 & & & & & 24.9 & 33.3 & \\
\hline & Lolium multiflorum & L.mul & & & & & 5.7 & 0.8 & & 4.0 & 4.7 & 36.8 & 24.6 & & 31.0 & 37.1 \\
\hline \multirow[t]{2}{*}{ GIP } & Chaetotropis elongata & Ch.elo & & & & & & & & 0.3 & & & & & & \\
\hline & $\begin{array}{l}\text { Hordeum } \\
\text { stenostachys }\end{array}$ & H.ste & & & & & & 1.0 & & & & & & & & \\
\hline \multirow[t]{3}{*}{ GEA } & A Digitaria ciliaris & D.cil & & & 1.0 & & & & & & & & & & & \\
\hline & Digitaria sanguinalis I & D.san & & 1.1 & 1.1 & & & & & & & & & & & \\
\hline & $\begin{array}{l}\text { Leptochloa fusca (ex } \\
\text { Diplachne uninervia) }\end{array}$ & L.fus & 3.6 & & 2.9 & 1.1 & & & 0.8 & & & & & & & \\
\hline \multirow[t]{14}{*}{ GEP } & Aristida murina & A.mur & & & & 1.0 & & & & & & & & & & \\
\hline & Bothiochloa laguroides & sB.lag & & & & 1.1 & 0.7 & & & & & & & & & \\
\hline & Cynodon dactylon & C.dac & 3.6 & 4.2 & & & & & & & & & & & & \\
\hline & Distichlis spicata & D.spi & & & 1.1 & 1.0 & & & & & & & & & & \\
\hline & Echinochloa colona & E.col & & & & 0.9 & 0.4 & & & & & & & & & \\
\hline & Eragrostis lugens & E.lug & & & 1.0 & 0.9 & 0.4 & & & & & & & & & \\
\hline & Panicum bergii & P.ber & & & 1.0 & 0.0 & 0.0 & & & & & 0.6 & & & & \\
\hline & Paspalum dilatatum & P.dil & & & & 0.6 & 2.0 & & & & & & & & 13.8 & \\
\hline & Setaria geniculata & S.gen & 3.6 & 3.3 & 1.9 & 5.2 & 14.2 & & & & & & 17.8 & & 22.0 & \\
\hline & Sporobolus indicus & S.in & & & & 1.0 & & & & & & & & 14.8 & & \\
\hline & Sporobolus platensis & S.pla & & & & 2.5 & 0.4 & & & 0.8 & & & & & & \\
\hline & $\begin{array}{l}\text { Sporobolus } \\
\text { pyramidatus }\end{array}$ & S.pyr & 47.6 & 20.8 & 8.6 & 5.6 & 1.2 & 7.5 & & 1.7 & & & 37.8 & & 36.9 & \\
\hline & $\begin{array}{l}\text { Stapfochloa (ex } \\
\text { Chloris) berroi }\end{array}$ & S.ber & & & 2.9 & 6.1 & 3.4 & & & & & & 19.3 & 18.2 & 14.1 & \\
\hline & $\begin{array}{l}\text { Steinchisma hians (ex } \\
\text { Panicum milioides) }\end{array}$ & s.hia & & & 11.4 & 3.3 & 7.9 & & & 3.3 & & & 17.9 & 18.7 & & \\
\hline \multirow[t]{10}{*}{$\mathrm{D}$} & $\begin{array}{l}\text { Acicarpha } \\
\text { procumbens }\end{array}$ & A.pro & & & & 1.4 & & 2.1 & & & & & & & & \\
\hline & $\begin{array}{l}\text { Acmella bellidioide } \\
\text { (ex Spilanthes) }\end{array}$ & A.bel & & 5.8 & & & 0.4 & & & 0.6 & & & & & & \\
\hline & Ambrosia tenuifolia & A.ten & & & & & 3.6 & & & & & & & & 15.2 & 15.2 \\
\hline & Apium leptophyllum & A.lep & & & 1.0 & 0.9 & 0.4 & & & & & & & & & \\
\hline & Baccharis notosergila & B.not & & & & & 1.3 & & & & & & & & & \\
\hline & $\begin{array}{l}\text { Calibrachoa parviflora } \\
\text { (ex Petunia) }\end{array}$ & C.par & & 4.2 & & 0.9 & 0.0 & 1.0 & 0.8 & & & & & & & \\
\hline & Chaptalia exscapa & Ch.exc & & & 0.9 & & 0.4 & & & & & & & & & \\
\hline & $\begin{array}{l}\text { Chevreulia } \\
\text { sarmentosa }\end{array}$ & Ch.sar & & & & 2.2 & 1.4 & & & & & & & & & \\
\hline & Conyza bonarensis & C.bon & & & & 1.9 & 4.8 & & 12.3 & & 0.7 & & & & & \\
\hline & Gamochaeta nivalis & G.niv & & & & & & 0.8 & & 1.6 & 2.1 & 0.5 & 14.9 & & & \\
\hline
\end{tabular}


Tabla 2. Continuación

Table 2. Continuation

\begin{tabular}{|c|c|c|c|c|c|c|c|c|c|c|c|c|c|c|c|}
\hline & $\begin{array}{l}\text { Grindelia pulchella } \\
\text { var. discoidea }\end{array}$ & G.pul & & & 4.9 & 3.8 & 4.0 & & & 3.7 & 3.9 & 6.3 & & 25.7 & 26.0 \\
\hline & $\begin{array}{l}\text { Jaegeria hirta (ex } \\
\text { Eclipta) }\end{array}$ & J.hir & & & 1.0 & 0.4 & & & & 0.3 & & & & & \\
\hline & $\begin{array}{l}\text { Lepidium } \\
\text { bonariense }\end{array}$ & L.bon & & 0.8 & & & 0.4 & 5.4 & 0.8 & 1.0 & & & & & \\
\hline & $\begin{array}{l}\text { Micropsis } \\
\text { spatulata }\end{array}$ & M.spa & & & & & & 1.7 & & & 0.6 & & & & \\
\hline & Oxalis sp. & O.sp & & & 0.9 & & & & & 0.9 & & & & & \\
\hline & $\begin{array}{l}\text { Phila nodiflora (ex } \\
\text { P. canescens) }\end{array}$ & P.nod & & 2.2 & & & 1.8 & & & 7.9 & 4.6 & 0.4 & & 20.2 & \\
\hline & $\begin{array}{l}\text { Plantago } \\
\text { heterophila }\end{array}$ & P.het & & & 1.0 & 0.9 & & & & & & & & & \\
\hline & Plantago myosurus & P.myo & & & & & & 13.3 & 5.7 & 5.4 & 0.7 & & 19.3 & & \\
\hline & $\begin{array}{l}\text { Pterocaulum } \\
\text { cordobensis }\end{array}$ & P.cor & & & 1.0 & 0.4 & 3.0 & & & & & & & & 14.0 \\
\hline & Soliva anthemifolia & S.ant & & & & 0.9 & & & & 4.2 & 2.1 & & & 16.7 & \\
\hline & $\begin{array}{l}\text { Soliva } \\
\text { macrocephala }\end{array}$ & S.mac & & & 1.0 & & & & & & & & & & \\
\hline & Spergula laevis & S.lae & 17.9 & 26.6 & 5.5 & 5.9 & 2.6 & 14.4 & 36.4 & 10.9 & 2.0 & 2.9 & & 46.4 & 50.8 \\
\hline \multirow[t]{7}{*}{ M } & Carex sp. & C.sp & & & & 0.6 & & & & & & & & & \\
\hline & $\begin{array}{l}\text { Cyperus } \\
\text { entrerrianus }\end{array}$ & C.ent & & 1.1 & & & & & & & & & & & \\
\hline & $\begin{array}{l}\text { Cyperus } \\
\text { meridionalis }\end{array}$ & C.mer & & & 1.0 & & 2.9 & & & 15.5 & 22.2 & 16.0 & 25.2 & 20.4 & 23.1 \\
\hline & Cyperus reflexus & C.ref & & 1.7 & 9.0 & 20.8 & 29.7 & & & & & & 23.3 & 21.9 & 19.7 \\
\hline & Juncus bufonius & J.buf & & & 4.8 & 3.1 & 1.3 & & & 2.7 & & & 22.1 & 21.9 & 14.6 \\
\hline & $\begin{array}{l}\text { Nothoscordum } \\
\text { inodorum }\end{array}$ & N.ino & & & 3.0 & & & & & & & & & & \\
\hline & $\begin{array}{l}\text { Zephyranthes } \\
\text { minima }\end{array}$ & Z.min & & & 1.0 & & & & & & & & & & \\
\hline \multirow[t]{2}{*}{$\mathrm{L}$} & Melilotus indicus & T.rep & & 3.8 & & 0.9 & 1.2 & & & & & & & & \\
\hline & Trifolium repens & M.ind & & & & & 1.8 & & & & & 1.0 & & & \\
\hline
\end{tabular}

parcelas no mostraron un patrón consistente. Por su parte, la equitatividad también fue mayor en el banco estival que en el invernal, pero no varió significativamente entre parcelas (Tabla 3). Los mismos patrones de variación se registraron al realizar el análisis a nivel de grupo funcional en lugar de especie (datos no mostrados).

\section{Diferencias florísticas entre parcelas y entre estaciones del año}

Se registraron diferencias florísticas entre los bancos de semilla de las parcelas sometidas a distintos sistemas de pastoreo. Los dos primeros ejes del ACP explicaron $49.5 \%$ del total de la varianza de los datos florísticos (31.8 y $17.7 \%$ para el primer y el segundo eje, respectivamente). El primer eje del ACP separó a los sitios bajo pastoreo continuo, con los valores más altos correspondientes a los sitios bajo pastoreo rotativo, y con los valores más bajos correspondientes a los excluidos al pastoreo. Dentro de los sitios con valores bajos en este eje, los muestreados en invierno tuvieron valores más bajos que los muestreados en verano. Por su parte, el segundo eje diferenció - dentro de los sitios bajo pastoreo continuo - el banco de invierno (con los valores más altos) del banco de verano (con los valores más bajos) (Figura 3a).

Once especies fueron las principales determinantes delaubicacióndelas36muestras de banco de semillas en los dos primeros ejes del ACP. Las especies determinantes de la ubicación contrapuesta de las parcelas bajo pastoreo continuo respecto a las otras en el primer eje del ACP (coeficiente de correlación entre la densidad relativa de cada especie y 
Tabla 3. Diversidad específica $\left(\mathrm{H}^{\prime}\right)$, riqueza florística (S) y equitatividad promedio del banco de semillas estival e invernal en parcelas bajo pastoreo continuo (C1 y C2), pastoreo rotativo (R1 y R2) y en la clausura (CL) de una estepa de halófitas. Se consignan los resultados del ANVA factorial realizado sobre los datos transformados (transformación angular para $\mathrm{H}$ y $\mathrm{E}$ y raíz cuadrada para $\mathrm{S} ;{ }^{* *}=\mathrm{P}<0.01 ; \mathrm{NS}=\mathrm{P}>0.10$ ). Letras distintas indican diferencias significativas entre las 10 combinaciones parcela $\mathrm{x}$ estación, en aquellos casos en que hubo interacción significativa entre ambos factores (prueba de Tukey, $\mathrm{P}<0.05$; letras ordenadas en forma creciente desde la media más baja hacia la más alta: A-B-C).

Table 3. Average specific diversity ( $\mathrm{H}^{\prime}$; angular transformed data), floristic richness (S; square root transformed data) and evenness (E; angular transformed data) recorded at the summer and winter seed banks in five plots of the halophytic steppe (C1 and C2 grazed continuously, R1 and R2 grazed rotationally and CL ungrazed). We report the Snedecor's F for the factors season, plot and the interaction season $x$ plot $\left.{ }^{* *}=\mathrm{P}<0.01 ; \mathrm{NS}=\mathrm{P}>0.10\right)$. When interaction was significant, different letters indicate the differences between the ten means compared (Tukey test, $\mathrm{P}<0.05$; letters ordered from the lowest to the highest mean: $\mathrm{A}<\mathrm{B}<\mathrm{C}$ ).

\begin{tabular}{|c|c|c|c|c|c|}
\hline \multicolumn{6}{|c|}{ Diversidad específica } \\
\hline & Estación & Parcela & Diversidad $\mathrm{H}^{\prime}$ & Riqueza S & Equitatividad E \\
\hline \multirow[t]{10}{*}{ Promedios } & Estival & $\mathrm{C} 1$ & $0.39 \mathrm{~A}$ & $3.00 \mathrm{~A}$ & 0.36 \\
\hline & & $\mathrm{C} 2$ & $0.67 \mathrm{AB}$ & $6.00 \mathrm{~A}$ & 0.38 \\
\hline & & $\mathrm{R} 1$ & $0.94 \mathrm{BC}$ & $11.50 \mathrm{~B}$ & 0.39 \\
\hline & & $\mathrm{R} 2$ & $0.99 \mathrm{C}$ & $13.75 \mathrm{~B}$ & 0.38 \\
\hline & & CL & $0.96 \mathrm{BC}$ & $15.00 \mathrm{~B}$ & 0.36 \\
\hline & Invernal & $\mathrm{C} 1$ & $0.62 \mathrm{AB}$ & $6.50 \mathrm{~A}$ & 0.33 \\
\hline & & $\mathrm{C} 2$ & $0.51 \mathrm{~A}$ & $4.75 \mathrm{~A}$ & 0.34 \\
\hline & & $\mathrm{R} 1$ & $0.90 \mathrm{BC}$ & $12.00 \mathrm{~B}$ & 0.36 \\
\hline & & $\mathrm{R} 2$ & $0.51 \mathrm{~A}$ & $6.50 \mathrm{~A}$ & 0.27 \\
\hline & & $\mathrm{CL}$ & $0.52 \mathrm{~A}$ & $5.00 \mathrm{~A}$ & 0.34 \\
\hline \multirow[t]{6}{*}{ ANVA } & Estación & $\mathrm{F}$ & 17.44 & 19.94 & 7.73 \\
\hline & & $\mathrm{P}$ & $* *$ & $* *$ & $* *$ \\
\hline & Parcela & $\mathrm{F}$ & 11.33 & 18.61 & 1.12 \\
\hline & & $\mathrm{P}$ & $* *$ & $* *$ & NS \\
\hline & $E \times P$ & $\mathrm{~F}$ & 9.72 & 14.77 & 1.06 \\
\hline & & $\mathrm{P}$ & $* *$ & $* *$ & NS \\
\hline
\end{tabular}

su valor en el eje analizado $[\mathrm{r}]>0.308$; g.l. $=38$; $\mathrm{P}<0.05)$ fueron dos gramíneas $\mathrm{C}_{3}$ anuales (Gaudinia fragilis y Lolium multiflorum), una dicotiledónea (Grindelia pulchella var. discoidea) y una monocotiledónea no gramínea (Cyperus meridionalis), con autovalores negativos (i.e., asociados a las parcelas no pastoreadas o pastoreadas rotativamente). Por su parte, en el otro extremo del primer eje del ordenamiento, las especies más importantes fueron las otras dos gramíneas anuales invernales (Haynardia [ex Monerma] cylindrica y Hordeum pusillum), una gramínea estival perenne (Sporobolus pyramidatus) y dos dicotiledóneas herbáceas (Spergula laevis y Lepidium bonariense), con autovalores positivos (i.e., asociados a las parcelas bajo pastoreo continuo). Estas últimas dos especies, junto con la mencionada Haynardia cylindrica y la dicotiledónea Plantago myosurus fueron claves también en el segundo eje, con autovalores positivos (i.e., asociadas al banco invernal de las parcelas sometidas a pastoreo continuo). Por su parte, las especies asociadas al banco estival en dichas parcelas fueron dos gramíneas estivales perennes (Setaria geniculata y la mencionada $S$. pyramidatus), todas con autovalores negativos (Figura 3b).

Los bancos de semillas de sitios provenientes de los dos potreros bajo pastoreo continuo no difirieron entre sí, y tampoco difirieron los provenientes de los dos potreros bajo pastoreo rotativo $(\mathrm{P}>0.20$ en ambos casos, prueba MRPP). Se encontraron diferencias florísticas entre los sitios clausurados y aquellos bajo pastoreo rotativo, y entre éstos y los sitios bajo pastoreo continuo. Asimismo, los sitios bajo pastoreo continuo fueron más heterogéneos internamente (distancia euclídea promedio 0.62) que los pastoreados rotativamente o los clausurados (d.e. promedio 0.43 y 0.53 , respectivamente; prueba MRPP). Por otra parte, el banco estival fue significativamente distinto al invernal $(\mathrm{P}<0.0001)$ y el primero fue algo más homogéneo que el segundo (d.e. promedio 0.55 y 0.63 , respectivamente; prueba MRPP).

Ocho especies indicadoras, cuatro de ellas importantes en el ACP, estuvieron asociadas a diferentes estaciones de 

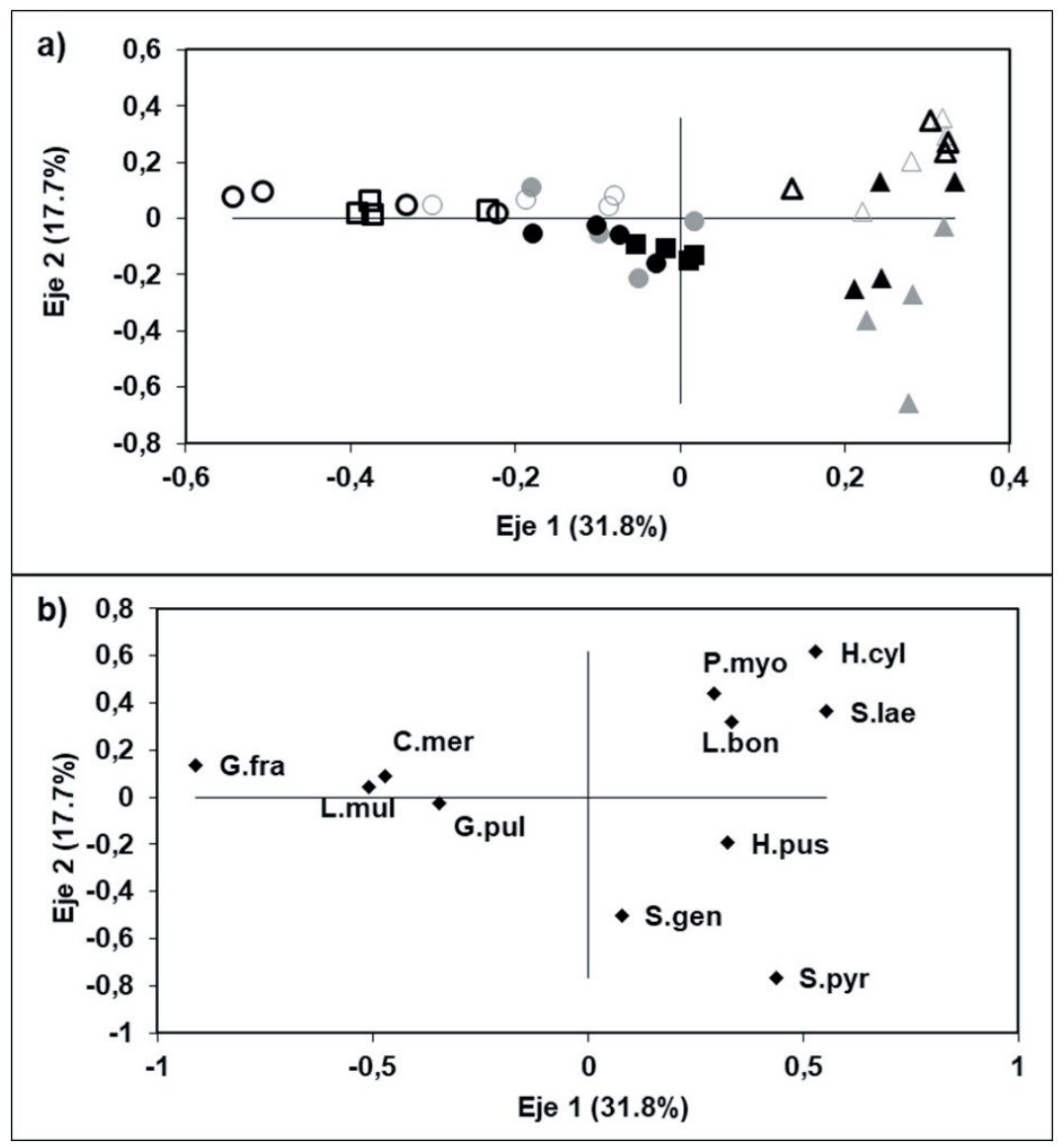

Figura 3. Resultados del análisis de componentes principales. (a) Ubicación de las 40 parcelas bajo estudio en el espacio definido por los dos primeros ejes. Símbolos llenos: banco estival; símbolos vacíos: banco invernal; triángulos: pastoreo continuo (grises C1, negros C2); cuadrados: clausura; círculos: pastoreo rotativo (grises R1, negros R2). (b) Coeficiente de correlación de Pearson entre la densidad relativa de cada especie en cada parcela y el valor de la parcela en cada uno de los dos ejes analizados. Los acrónimos incluyen la inicial del género y las tres primeras letras de la especie, separados por un punto (ver nombres completos en la Tabla 2). Sólo se incluyen las especies que mostraron correlaciones significativas $(\mathrm{P}<0.05)$ en alguno de los ejes.

Figure 3. Principal component analysis. (a) Distribution of the 40 samples along the space defined by the first two axes. Full symbols: summer bank; empty symbols: winter bank; triangles: continuous grazing (grey C1, black C2); squares: ungrazed; circles: rotational grazing (grey R1, black R2). (b) Pearson's correlation coefficient between relative density of each species in each sampling unit and the score of the sampling on each PCA axis. Acronyms include the first letter of genus and the three first letters of the species separated by a point (see complete names in Table 2). Only the species with significant correlations with at least one axis were included.

muestreo (VI estacional, $\mathrm{P}<0.01$ ) (Tabla 2). La monocotiledónea Cyperus meridionalis y las dicotiledóneas Plantago myosurus y Gamochaeta nivalis (las dos primeras, importantes en el $\mathrm{ACP}$ ) fueron mucho más abundantes en el banco invernal que en el estival, mientras que las gramíneas perennes Setaria geniculata, Sporobolus pyramidatus y Stapfochloa berroi (las dos primeras importantes en el ACP) y las monocotiledóneas Cyperus reflexus y Juncus bufonius fueron más abundante en el banco estival que en el invernal (VI estacional) (Tabla 2).
Del mismo modo, siete especies del banco (tres de ellas importantes en el ACP) mostraron distribuciones diferenciales en las parcelas bajo pastoreo continuo o bajo pastoreo rotativo. Gaudinia fragilis, Grindelia pulchella y Cyperus meridionalis (importantes en el ACP) más Stapfochloa berroi, Steinchisma hians, Cyperus reflexus y Juncus bufonius fueron más abundante en las parcelas bajo pastoreo rotativo que en aquéllas bajo pastoreo continuo, y ninguna especie fue significativamente más abundante bajo pastoreo continuo que bajo pastoreo rotativo (VI R/C) (Tabla 2). 
Por su parte, ocho especies, cinco de ellas importantes en el ACP, diferenciaron los sitios clausurados de los pastoreados en forma continua. Haynardia cylindrica* fue más abundante bajo pastoreo continuo, mientras que Gaudinia fragilis*, Lolium multiflorum*, Grindelia pulchella*, Ambrosia tenuifolia, Cyperus meridonalis*, Cyperus reflexus y Juncus bufonius fueron más abundantes en los sitios clausurados (los asteriscos indican las 4 importantes en el ACP; VI CL/C; $\mathrm{P}<0.05$ ) (Tabla 2).

Finalmente, sólo tres especies (dos de ellas importantes en el ACP) mostraron diferente comportamiento en las parcelas sin pastoreo y en aquéllas bajo pastoreo rotativo. Gaudinia fragilis $^{*} \mathrm{y} A$. tenuifolia fueron más abundantes bajo clausura que bajo pastoreo rotativo. Por su parte, H. cylindrica* mostró el comportamiento opuesto, recordando por supuesto que esta especie presenta su máxima abundancia en el banco de semillas de las parcelas sometidas a pastoreo continuo (los asteriscos indican las 4 importantes en el $\mathrm{ACP}$; VI R/CL; $\mathrm{P}<0.05$ ) (Tabla 2).

\section{Discusión}

Nuestro trabajo muestra que, en la estepa de halófitas de la Depresión del Salado, el banco de semillas de las parcelas bajo pastoreo continuo fue mucho más afectado que el de las parcelas bajo pastoreo rotativo, y que los patrones detectados en el banco de semillas de las parcelas bajo pastoreo rotativo fueron muy similares a los de las áreas excluidas al pastoreo. Esta similitud marcada entre las parcelas pastoreadas rotativamente y las no pastoreadas refuerza los resultados obtenidos al comparar los caracteres de la vegetación establecida y los suelos en la misma comunidad, en mucho mejor condición en esas parcelas que en las pastoreadas continuamente (Vecchio et al. 2018, 2019).

Más allá de la estación en que se extrajo la muestra de banco de semillas, las parcelas bajo pastoreo continuo presentaron un banco de semillas mucho más pequeño (objetivo 1 ), con menor densidad absoluta de gramíneas anuales y monocotiledóneas no gramíneas (objetivo 2), menor diversidad y riqueza florística (aunque sólo en el banco estival) (objetivo 3), y diferencias florísticas respecto a las parcelas no pastoreadas o pastoreadas rotativamente, evidenciadas a lo largo del eje 1 del ACP (objetivo 4). $\mathrm{Al}$ respecto, se detectaron especies indicadoras de los tres sistemas de pastoreo.
Entre las gramíneas anuales se destacaron Haynardia cylindrica y Hordeum pusillum en las parcelas bajo pastoreo continuo; Gaudinia fragilis en las parcelas bajo pastoreo rotativo (y algo menos abundantes en las clausuras, sobre todo en el BSE) y Lolium multiflorum en las clausuras (las cuatro especies, invernales). Entre las gramíneas perennes, Stapfochloa berroi y Steinchisma hians (ex Panicum milioides) (todas estivales) aparecieron sólo en las parcelas bajo pastoreo rotativo o no pastoreadas. Entre las dicotiledóneas, Ambrosia tenuifolia apareció sólo en la parcela no pastoreada y Grindelia pulchella lo hizo en ésa y en las parcelas bajo pastoreo rotativo. Finalmente, entre las monocotiledóneas, Cyperus meridionalis, Cyperus reflexus y Juncus bufonius aparecieron solamente en las parcelas bajo pastoreo rotativo y sin pastoreo.

Independientemente del régimen de pastoreo, el banco invernal fue más abundante que el estival (objetivo 1), con más gramíneas invernales anuales y menos gramíneas estivales, tanto anuales como perennes (objetivo 2), y cierta tendencia a presentar menor diversidad, riqueza florística y equitatividad (objetivo 3). Ambos bancos estacionales mostraron diferencias en cuanto a la composición florística, evidentes sobre el eje 1 del ACP para las parcelas no pastoreadas o bajo pastoreo rotativo, y sobre el eje 2 para las parcelas bajo pastoreo continuo. Las gramíneas anuales, tanto invernales como estivales, aparecieron por igual en las dos estaciones de muestreo. Entre las gramíneas perennes, Setaria geniculata, Sporobolus pyramidatus y Stapfochloa berroi (todas estivales) aparecieron principalmente en el banco estival. En cambio, las dicotiledóneas Gamochaeta nivalis y Plantago myosurus aparecieron sólo en el banco invernal. Por último, entre las monocotiledóneas, Cyperus meridionalis fue más abundante en el banco invernal, mientras que Cyperus reflexus y Juncus bufonius lo fueron en el estival.

El pastoreo continuo puede modificar la estructura de las comunidades vegetales a través de su efecto sobre el banco de semillas, entre otros efectos (Noy-Meir 1990; Fernández et al. 1992; Bertiller 1996). El efecto del pastoreo continuo sobre el banco de semillas obedece a que las plantas pastoreadas producen menos semillas, induciendo una reducción de la colonización por plántulas (Smith et al. 2000) y un agotamiento del banco (Hodgkinson 1992). Asimismo, el efecto puede ser aun más grave en los parches sobrepastoreados, 
donde puede desencadenar la eventual extinción de las especies forrajeras de pastos perennes. De este modo, es posible que ocurra una retroalimentación positiva, con consecuencias negativas para la comunidad (comúnmente, 'círculo vicioso'), generando el empobrecimiento o agotamiento de las semillas del banco de semillas del suelo (Tessema et al. 2016). En las praderas húmedas de mesófitas de la Depresión del Salado se describieron cambios similares en el banco de semillas, tanto bajo distintos sistemas de pastoreo (Rodríguez and Jacobo 2010) como bajo la acción de herbicidas para promover la instalación temprana de especies invernales (Rodríguez and Jacobo 2013). En cambio, hasta el momento no había trabajos que describieran el banco de semillas en parcelas sometidas a diferentes modalidades de pastoreo en las estepas de halófitas de la región.

En la comunidad de halófitas estudiada, el banco de semillas de las parcelas bajo pastoreo continuo tuvo menos densidad de especies monocotiledóneas y gramíneas invernales anuales, tanto en la estación fría como en la estación cálida, que los bancos de aquellas parcelas bajo pastoreo rotativo o no pastoreadas (Tabla 2). Las especies anuales invernales constituyen un grupo muy importante porque representa más de la mitad de las semillas presentes en el banco, tanto estival como invernal, aunque está representado por sólo cuatro especies. Contrariamente a lo esperado, nuestros resultados indican que las principales diferencias entre el banco de semillas de parcelas sometidas a distintos regímenes de pastoreo o en diferentes estaciones del año no estuvieron asociadas a cambios en la importancia relativa de los distintos grupos funcionales (excepto los mencionados para las monocotiledóneas y las gramíneas invernales anuales), sino - como se señaló más arriba - a la dominancia de distintas especies en las parcelas sometidas a pastoreo continuo respecto a aquellas sometidas a pastoreo rotativo o no pastoreadas.

El fenómeno del cambio de especies dominantes dentro de los distintos grupos funcionales fue particularmente evidente dentro de las gramíneas invernales anuales (Haynardia cylindrica y Hordeum pusillum vs. Lolium multiflorum y Gaudinia fragilis, respectivamente) y de las gramíneas estivales perennes (Stapfochloa berroi y Steinchisma hians, sólo presentes en el segundo grupo de parcelas). Es posible que esas diferencias florísticas sean reflejo del cambio florístico que se registró en la comunidad vegetal establecida al pasar de pastoreo continuo a pastoreo rotativo o exclusión del pastoreo (Vecchio et al. 2019). Asimismo, la presencia de S. berroi en las parcelas sometidas a menor intensidad de disturbio coincide con su aparición en la vegetación establecida de las mismas. En cambio, llama la atención la ausencia de semillas de Distichlis spp. en el banco de las parcelas bajo pastoreo continuo, donde esta especie es dominante. Las mejores condiciones de fertilidad edáfica en las parcelas excluidas al pastoreo o pastoreadas rotativamente (Vecchio et al. 2018) probablemente hayan permitido la germinación y establecimiento de Lolium multiflorum, Gaudinia fragilis, Stapfochloa berroi y Steinchisma hians, especies de ambientes más fértiles que la estepa de halófitas (las dos primeras, invernales, y las dos segundas, estivales). Por el contrario, no sorprende la presencia de Haynardia cylindrica y Hordeum pusillum en las parcelas bajo pastoreo continuo porque son especies que se benefician en ambientes pobres, desnudos, donde la mayoría de las especies no podría germinar y establecerse.

Las parcelas estudiadas se ordenan en un gradiente de disturbio creciente desde las no pastoreadas a las pastoreadas continuamente, con las pastoreadas rotativamente en una posición intermedia (Tabla 2 y 3). Las marcadas similitudes entre las pastoreadas rotativamente y las no pastoreadas halladas tanto en este trabajo como en los relevamientos previos de suelo (Vecchio et al. 2018) y vegetación (Vecchio et al. 2019) sugeriría que son los disturbios más intensos los que alteran la estructura de la vegetación y, en consecuencia, la del suelo y la del banco de semillas. En efecto, como resultado de los cambios florísticos descriptos para el banco de semillas, las parcelas bajo pastoreo continuo no sólo tuvieron menor densidad de semillas, sino también menor riqueza de especies. Tal disminución de la riqueza del banco de semillas en los sitios más disturbados se relaciona con la extinción local de 31 especies, en su mayoría nativas o naturalizadas. Entre ellas se encuentran 14 especies de gramíneas (3 invernales y 11 estivales, incluyendo anuales y perenes en ambos grupos), 12 dicotiledóneas y 5 monocotiledóneas no gramíneas. Por esta razón, se puede considerar que el pastoreo continuo es una perturbación grave responsable de la pérdida de riqueza y de diversidad de semillas (Kassahun et al. 2009; Rodríguez and Jacobo 2013). A su vez, 
esto afecta la conservación de la diversidad de las comunidades vegetales (Fisher et al. 2009), ya que muchas especies herbáceas, tanto gramíneas como dicotiledóneas, se regeneran a partir del banco de semillas (Wang et al. 2020).

El tamaño de los bancos de semillas varía según la composición de la vegetación natural de cada comunidad y del disturbio o del manejo recibido. Nuestros resultados contradicen en gran medida algunos patrones relativamente generales que figuran en la literatura. Estudios realizados en pastizales alcalinos no salinos del centro este de Europa, bajo pastoreo moderado, registraron una densidad media del banco de semillas de 30000 a 51000 semillas/ $\mathrm{m}^{2}$, que es más alta que la encontrada en la mayoría de los pastizales secos, pero más baja que la registrada en pastizales salinos (Valkó et al. 2014). Además, muestran que el pastoreo moderado es un requisito importante para el mantenimiento de la vegetación halófita (Dítětová et al. 2016). Trabajos efectuados en diversos pastizales de nuestro país citan un rango de densidad de semillas relativamente corriente para bancos de áreas clausuradas al pastoreo de 300 a 5000 semillas/m² (Haretche and Rodríguez 2006), muy inferiores a los arriba mencionaos. Dichos valores, además, aumentan de manera considerable cuando las áreas son pastoreadas (Bertiller 1996; Funes et al. 2001; Marco and Páez. 2000; Loydi 2019; Marone and Pol 2021). En nuestro trabajo registramos densidades de semillas más altas que las encontradas en otros pastizales de nuestro país clausurados al pastoreo, pero más bajas que las de pastizales salinos y alcalinos europeos. Asimismo, los sitios pastoreados de forma continua presentaron una menor densidad de semillas en el banco que los clausurados o pastoreados rotativamente. El tamaño relativamente grande del banco de semillas en la estepa de halófitas comparado con otros pastizales de la Argentina tal vez esté asociado a la abundancia de especies anuales invernales potencialmente capaces de generar un elevado número de semillas (Ghermandi 1992).

Una característica de los bancos de semillas de otros pastizales del mundo es la presencia de un número apreciable de semillas viables de dicotiledóneas, mientras que el número de semillas de leguminosas tiende a ser bajo comparado con los de otros grupos funcionales (Roberts 1981). Esto concuerda con lo obtenido en nuestro trabajo, en el que se obtuvo en los sitios bajo pastoreo un porcentaje de dicotiledóneas entre 19\% y 46\% en el banco estival e invernal, respectivamente (PC: 29-47\%; PR: 18-27\% CL: 24-10\%), mientras que las leguminosas no superaron el $4 \%$ en ningún caso. Dentro de las leguminosas, llama la atención la presencia de Trifolium repens en las áreas excluidas al pastoreo, ya que esta especie vegeta en suelos ácidos y muy orgánicos, muy alejados de las condiciones típicas de los suelos Natracualf característicos de la estepa de halófitas. Sin embargo, la presencia incipiente de $T$. repens en el banco de semillas de las áreas no pastoreadas concuerda con el aumento significativo del contenido de materia orgánica registrado en los suelos de las clausuras (Vecchio et al. 2018).

Más allá del método de pastoreo utilizado, el banco invernal fue mayor que el estival. Sin dudas, una de las causas de tal diferencia fue el aporte de las gramíneas invernales anuales. En cambio, las gramíneas invernales perennes estuvieron prácticamente ausentes. Por un lado, esto se podría explicar porque las plantas anuales a menudo forman bancos de semillas persistentes y abundantes debido a que su supervivencia depende del éxito en la regeneración desde el banco (Gordon 2000). Por otra parte, al ser pequeñas, estas semillas son enterradas más fácilmente y representan un alimento menos accesible para los depredadores (Hulme 1998). En tercer lugar, requieren mayor estímulo lumínico para poder germinar (Milberg et al. 2000; Tessema et al. 2016).

Salvando las limitaciones en el diseño experimental, nuestros resultados muestran por primera vez los cambios en el banco de semillas entre parcelas con stands de estepas de halófitas sometidos a distinta intensidad de pastoreo. En particular, sugieren que el pastoreo continuo la estepa de halófitas de la Depresión del Salado cambia la composición de las especies, la riqueza y la diversidad florística del banco de semillas. Estos cambios en el banco de semillas están acompañados por un deterioro de las propiedades edáficas (Vecchio et al. 2018) y, además, implican la extinción local de plantas perennes nativas y naturalizadas. En consecuencia, la restauración dela comunidad dependería principalmente de mejorar la salud del suelo (i.e., con descansos prolongados o periódicos) (Vecchio et al. 2018) y de la dispersión de propágulos desde las áreas adyacentes. Nuestros resultados ponen de manifiesto los riesgos para la conservación de la biodiversidad al aplicar el pastoreo continuo en hábitats tan restrictivos 
como la estepa de halófitas. Además, brindan información complementaria a trabajos previos (Vecchio et al. 2018, 2019) que sugieren que el sobrepastoreo tiene consecuencias para la producción ganadera en pastizales halófitos de la Depresión del Salado. La productividad primaria neta de la comunidad se concentra principalmente durante la primavera y el verano, época en la que producen sus semillas las especies invernales $\mathrm{y}$, principalmente, las estivales. Por lo tanto, aplicar el pastoreo continuo pone en riesgo la condición de la comunidad halofítica al afectar la reproducción de muchas de las especies preferidas. La aplicación de un método de pastoreo que contemple descansos planificados permite aumentar la cobertura total mediante el aumento de la cobertura vegetal y de la broza (Vecchio et al. 2019), recuperar el vigor de las especies de valor forrajero, disminuir la selectividad y promover la germinación y el establecimiento, así como la floración y fructificación de especies deseadas. Esto se podría lograr dando descansos planificados entre 60 a 150 días (más cortos cuanto mayor sea la tasa de crecimiento del pastizal), con períodos de permanencia cortos (3 a 5 días) y altas cargas instantáneas (Vecchio and Refi 2019). Tanto los tiempos de ocupación como los de descanso deben ser flexibles y tener en cuenta las condiciones de exceso o déficit hídrico del suelo para decidir el ingreso y la permanencia de los animales.

Agradecimientos. Este trabajo fue financiado por la Secretaría de Ciencia y Tecnología de la Universidad Nacional de La Plata, Buenos Aires (Proyecto PID 11 / A234). Agradecemos muy especialmente al Dr. Néstor Bayón por su valiosa contribución en la identificación de las especies vegetales y a las Ing. Agr. Rita Lettieri y Anahí Musso por su colaboración en las mediciones.

\section{REFERENCIAS}

Abernethy, V. J., and N. J. Willby. 1999. Changes along a disturbance gradient in the density and composition of propagule banks in floodplain aquatic habitats. Plant Ecology 140:177-190. https://doi.org/10.1023/A:1009779411686.

Bertiller, M. B. 1996. Seasonal variation in the seed bank of Patagonian grassland in relation to grazing and topography. Journal of Vegetation Science 3:47-54. https://doi.org/10.2307/3235997.

Biondini, M. E., B. D. Patton, and P. E. Nyren. 1998. Grazing intensity and ecosystem process in a northern mixed-grass prairie, USA. Ecological Applications 8:469-479. https://doi.org/10.1890/1051-0761(1998)008[0469:GIAEPI]2.0.CO;2.

Bolaños, V. R., M. C. Vecchio, and R. A. Golluscio. 2019. Temperaturas de germinación de cuatro gramíneas nativas del pastizal halofítico de la Pampa Deprimida, Argentina. Ecología Austral 29:249-260. https://doi.org/10.25260/ EA.19.29.2.0.788.

Braun-Blanquet, J. 1979. Fitosociología. Bases para el estudio de las comunidades vegetales. Blume Ediciones, Madrid.

Burkart, S. E., M. F. Garbulsky, C. M. Ghersa, J. P. Guerschman, J. C. R. León, M. Oesterheld, J. M. Paruelo, and S. B. Perelman (ex aequo). 2005. Las comunidades potenciales del pastizal pampeano bonaerense. Pp. 379-387 in M. Oesterheld, M. Aguiar, C. Ghersa and J. Paruelo (eds.). La Heterogeneidad de la Vegetación de los Agroecosistemas. Un Homenaje a Rolando León. Facultad de Agronomía, UBA. Buenos Aires, Argentina.

Chambers, J. C., and J. A. MacMahon. 1994. A day in the life of a seed: movements and fates of sedes and theirs implications for natural and management systems. Annual Review of Ecology and Systematics 25:263-292. https: //doi.org/10.1146/annurev.es.25.110194.001403.

Chaneton, E. J., S. B. Perelman, M. Omacini, and R. J. C. Léon. 2002. Grazing, environmental heterogeneity, and alien plant invasions in temperate Pampa grasslands. Biological Invasions 4:7-24. https://doi.org/10.1023/A:1020536728448.

Di Rienzo, J. A., F. Casanoves, M. G. Balzarini, L. González, M. Tablada, and C. W. Robledo. 2018. InfoStat versión 2018. Centro de Transferencia InfoStat, FCA, Universidad Nacional de Córdoba, Argentina.

Dítětová, Z., D. Dítě, E. Pavol, and G. Dobromil. 2016. The impact of grazing absence in inland saline vegetation - a case study from Slovakia. Biologia 71:980-988. https://doi.org/10.1515/biolog-2016-0125.

Fernández, R. J., A. H. Núñez, and A. Soriano. 1992. Contrasting demography of two Patagonian shrubs under different conditions of sheep grazing y resource supply. Oecologia 91:39-46. https://doi.org/10.1007/BF00317238.

Fisher, J., W. Loneragan, K. Dixon, and E. Veneklass. 2009. Soil seed bank compositional change constrains biodiversity in an invaded species-rich woodland. Biological Conservation 142:256-269. https://doi.org/10.1016/ j.biocon.2008.10.019.

Funes, G., S. Basconcelo, S. Díaz, and M. Cabido. 2001. Edaphic patchiness influences grassland regeneration from the soil seed-bank in mountain grasslands of central Argentina. Austral Ecology 26:205-212. https://doi.org/10.1046/ j.1442-9993.2001.01102.x.

Ghermandi, L. 1992. Caracterización del banco de semillas de una estepa en el noroeste de Patagonia. Ecología Austral 2:39-46.

Gioria, M., V. Jarosík, and P. Pyšek. 2014. Impact of invasions by alien plants on soil seed bank communities: emerging patterns. Perspectives in Plant Ecology 16:132-142. https://doi.org/10.1016/j.ppees.2014.03.003. 
Gordon, E. 2000. Dinámica de la vegetación y del banco de semillas en un humedal herbáceo lacustrino (Venezuela). Revista de Biología Tropical 48(1):25-42.

Haretche, F., and C. Rodríguez. 2006. Banco de semillas de un pastizal uruguayo bajo diferentes condiciones de pastoreo. Ecología Austral 16:105-113.

Henderson, C. B., K. E. Petersen, and R. A. Redak. 1988. Spatial and temporal patterns in the seed bank and vegetation of a desert grassland community. Journal of Ecology 76:717-728. https://doi.org/10.2307/2260569.

Hopfensperger, K. N. 2007. A review of similarity between seed bank and standing vegetation across ecosystems. Oikos 116:1438-1448. https://doi.org/10.1111/j.0030-1299.2007.15818.x.

Hodgkinson, K. C. 1992. Elements of grazing strategies for perennial grass management in Rangelands. Pp. 77-94 in G. P. Chapman (ed,). Desertified Grasslands: their Biology and Management (Linnean Society Symposium Series No 13). London. Academic Press.

Hulme, P. E. 1998. Post-dispersal seed predation and seed bank persistence. Seed Science Research 8:513-519. https: //doi.org/10.1017/S0960258500004487.

Hurlbert, S. H. 1984. Pseudoreplication and the Design of Ecological Field Experiments. Ecological Monographs 54(2): 187-211. https://doi.org/10.2307/1942661.

Jacobo, E. J., A. M. Rodríguez, N. Bartoloni, and V. A. Deregibus. 2006. Rotational grazing. Effects on Rangeland Vegetation at a Farm scale. Rangeland Ecology and Management 59:249-257. https://doi.org/10.2111/05-129R1.1.

Kassahun, A., H. A Snyman, and G. N. Smit. 2009. Soil seed bank evaluation along a degradation gradient in arid rangelands of the Somali region, eastern Ethiopia. Agriculture, Ecosystems and Environment 129:428-436. https: //doi.org/10.1016/j.agee.2008.10.016

Laterra, P., L. Ricci, O. Vignolio, and O. N. Fernández. 1994. Efectos del fuego y del pastoreo sobre la regeneración por semillas de Paspalum quadrifarium en la Pampa Deprimida, Argentina. Ecología Austral 4:101-109.

Lavado, R. S., and M. A. Taboada. 1988. Water, SALT and sodium dynamics in a Natraquoll in Argentina. Catena 15: 577-594. https://doi.org/10.1016/0341-8162(88)90008-2.

Legendre, P., and L. Legendre. 1998. Numerical Ecology. Elsevier: Amsterdam. Pp. 853.

León, R. J. C., S. Burkart, and C. P. Movia. 1979. Relevamiento fitosociológico del pastizal del Norte de la Depresión del Salado. Serie Fitogeografica 17. I.N.T.A. Buenos Aires. Pp. 90.

Loydi, A., S. M. Zalba, and R. A. Diltel. 2012. Viable seed banks under grazing and exclosure conditions in montane mesic grasslands of Argentina. Acta Oecologica 43:8-15. https://doi.org/10.1016/j.actao.2012.05.002.

Loydi, A. 2019. Effects of grazing exclusion on vegetation and seed bank composition in a mesic mountain grassland in Argentina. Plant Ecology and Diversity 12(2):127-138. https://doi.org/10.1080/17550874.2019.1593544.

Magurran, A. E. 2004. Introduction: measurement of (biological) diversity. Pp. 1-17 in A. E. Magurran (ed.). Measuring Biological Diversity. Blackwell Publishing, UK.

Marco, D. E., and S. A. Páez. 2000. Soil Seed Banks on Argentine Seminatural Mountain Grasslands After Cessation of Grazing. Mountain Research and Development 20(3):254-261. https://doi.org/10.1659/0276-4741(2000)020[0254: SSBOAS]2.0.CO;2.

Mac Graw, J., and M. Varek. 1989. The Role of Burried Viable Seeds in Artic and Alpin Communities. Pp. 91-105 in M. Leck, V. Parker and L. Simpson (eds.). Ecology of Soil Seed Bank. Academic Press, San Diego, California. https: //doi.org/10.1016/B978-0-12-440405-2.50011-7.

Marone, L., and R. G. Pol. 2021. Continuous grazing disrupts desert grass-soil seed bank composition under variable rainfall. Plant Ecology 222:247-259. https://doi.org/10.1007/s11258-020-01102-4.

McCune, B., and M. J. Mefford. 1999. Multivariate Analysis of Ecological Data. Version 4.0. MJM Software, Gleneden Beach, Oregon.

Márquez, S., G. Funes, M. Cabido, and E. Pucheta. 2002. Efecto del pastoreo sobre el banco de semillas germinable y la vegetación establecida en pastizales de montaña del centro de Argentina. Revista Chilena de Historia Natural 75: 327-337. https://doi.org/10.4067/S0716-078X2002000200006.

Milberg, P., L. Andersson, and K. Thompson. 2000. Large-seeded species are less dependent on light for germination than small-seeded ones. Seed Science Research 10(1):99-104. https://doi.org/10.1017/S0960258500000118.

Noble, I. R., and H. Gitay. 1996. A functional classification for predicting the dynamics of landscapes. Journal of Vegetation Science 7:329-336. https://doi.org/10.2307/3236276.

Noy-Meir, I. 1990. Responses of two semiarid rangeland communities to protection from grazing. Israel Journal of Botany 39:431-442.

O'Connor, T. G. 1991. Local extinction in perennial grasslands: a life-history approach. American Naturalist 137:753773. https://doi.org/10.1086/285192.

O'Connor, T. G., and S. T. A. Pickett. 1992. The influence of grazing on seed production and seed banks of some African savanna grasslands. Journal of Applied Ecology 29:247-260. https://doi.org/10.2307/2404367.

Oyarzabal, M., J. Clavijo, L. Oakley, F. Biganzoli, P. Tognetti, I. Barberis, H. M. Maturo, R. Aragón, P. I. Campanello, D. Prado, M. Oesterheld, and R. León. 2018. Unidades de Vegetación de la Argentina. Ecología Austral 28:040-063. https://doi.org/10.25260/EA.18.28.1.0.399.

Perelman, S. B., R. J. C. León, and M. Oesterheld. 2001. Cross-Scale vegetation patterns of Flooding Pampa grasslands. Journal of Ecology 89:562-577. https://doi.org/10.1046/j.0022-0477.2001.00579.x.

Puhl, L. E., S. B. Perelman, W. B. Batista, S. E. Burkart, and R. J. C. Léon. 2014. Local and regional long-term diversity 
changes and biotic homogenization in two temperate grasslands. Journal of Vegetation Science 25:1278-1288. https: //doi.org/10.1111/jvs.12179.

Real, R., and J. M. Vargas. 1996. The probabilistic basis of Jaccard's index of similarity. Systematic Biology 45(3):380385. https://doi.org/10.1093/sysbio/45.3.380.

Roberts, H. A. 1981. Seed Banks in soils. Advances in Applied Biology 6:1-55.

Rodríguez, A. M., and E. Jacobo. 2010. Glyphosate effects on floristic composition and species diversity in the Flooding Pampa grassland (Argentina). Agriculture, Ecosystems and Environment 138:222-231. https://doi.org/10.1016/ j.agee.2010.05.003.

Rodríguez, A. M., and E. Jacobo. 2013. Glyphosate effects on seed bank and vegetation composition of temperate grasslands. Applied Vegetation Science 16:51-62. https://doi.org/10.1111/j.1654-109X.2012.01213.x.

Shannon, C. E., and W. W. Weaver. 1963. The mathematical theory of communications. University of Illinois Press, Urbana. Pp 117.

Smith, S. E., R. Mosher, and D. Fendenheim. 2000. Seed production in sideoats grama populations with different grazing histories. Journal of Range Management 53:550-555. https://doi.org/10.2307/4003657.

Tessema, Z. K., W. F. B. Boer, and H. H. T. Prins. 2016. Changes in grass plant populations and temporal soil seed bank dynamics in a semi-arid African savanna: implications for restoration. Journal of Environmental Management 182: 166-175. https://doi.org/10.1016/j.jenvman.2016.07.057.

Thompson, K. 1992. The functional ecology of seed banks. Pp. 231-258 in M. Fenner (ed.). Seeds. The Ecology of Regeneration in Plant Communities. C.A.B. International. Wallingford, UK.

Valkó, O., B. Tóthmérész, A. Kelemen, E. Simon, T. Miglécz, B. Lukács, and P. Török. 2014. Environmental factors driving seed bank diversity in alkali grasslands, Agriculture, Ecosystems and Environment 182:80-87. https://doi.org/ 10.1016/j.agee.2013.06.012.

Vecchio, M. C., R. Golluscio, A. Rodríguez, and M. A. Taboada. 2018. Improvement of saline-sodic grassland soil properties by rotational grazing in Argentina. Rangeland Ecology and Management 71(6):807-814. https://doi.org/ 10.1016/j.rama.2018.04.010.

Vecchio, M. C., V. R. Bolaños, R. Golluscio, and A. Rodríguez. 2019. Rotational grazing and exclosures improves grassland condition of the halophytic steppe in Flooding Pampa (Argentina) compared with continuous grazing. The Rangeland Journal 41(1):1-12. https://doi.org/10.1071/RJ18016.

Vecchio, M. C., and R. Refi. 2019. Ganadería bovina de ciclo completo, agricultura permanente y rotación agrícolaganadera en la transición Pampa Ondulada - Pampa Deprimida. Proyecto Institucional para el Desarrollo Tecnológico y Social. Exp N²00-3192/17. Resolución Nº 168. Facultad de Ciencias Agrarias y Forestales. UNLP.

Wang, N., X. He, F. Zhao, D. Wang, and J. Jiao. 2020. Soil seed bank in different vegetation types in the Loess Plateau region and its role in vegetation restoration. Restoration Ecology 28:A5-A12. https://doi.org/10.1111/rec.13169. 